\title{
Alkaloids Profiling of Fumaria capreolata by Analytical Platforms Based on the Hyphenation of Gas Chromatography and Liquid Chromatography with Quadrupole-Time-of-Flight Mass Spectrometry
}

\author{
María del Mar Contreras, ${ }^{1,2}$ Noureddine Bribi, ${ }^{3,4}$ Ana María Gómez-Caravaca, ${ }^{2}$ \\ Julio Gálvez, ${ }^{3}$ and Antonio Segura-Carretero ${ }^{1,2}$ \\ ${ }^{1}$ Research and Development Functional Food Centre (CIDAF), Bioregión Building, Health Science Technological Park, \\ Avenida del Conocimiento s/n, 18016 Granada, Spain \\ ${ }^{2}$ Department of Analytical Chemistry, Faculty of Sciences, University of Granada, Avda. Fuentenueva s/n, 18071 Granada, Spain \\ ${ }^{3}$ CIBER-EHD, Department of Pharmacology, ibs.GRANADA, Center for Biomedical Research (CIBM), University of Granada, \\ Avenida del Conocimiento s/ $n$, Armilla, 18016 Granada, Spain \\ ${ }^{4}$ Laboratoire de Biotechnologies Végétales et Ethnobotanique, Faculté des Sciences de la Nature et de la Vie, \\ Université de Bejaia, 06000 Bejaia, Algeria
}

Correspondence should be addressed to María del Mar Contreras; mar.contreras.gamez@gmail.com and Antonio Segura-Carretero; ansegura@ugr.es

Received 29 April 2017; Accepted 2 July 2017; Published 28 November 2017

Academic Editor: Mohamed Abdel-Rehim

Copyright ( 2017 María del Mar Contreras et al. This is an open access article distributed under the Creative Commons Attribution License, which permits unrestricted use, distribution, and reproduction in any medium, provided the original work is properly cited.

\begin{abstract}
Two analytical platforms, gas chromatography (GC) coupled to quadrupole-time-of-flight (QTOF) mass spectrometry (MS) and reversed-phase ultrahigh performance liquid chromatography (UHPLC) coupled to diode array (DAD) and QTOF detection, were applied in order to study the alkaloid profile of Fumaria capreolata. The use of these mass analyzers enabled tentatively identifying the alkaloids by matching their accurate mass signals and suggested molecular formulae with those previously reported in libraries and databases. Moreover, the proposed structures were corroborated by studying their fragmentation pattern obtained by both platforms. In this way, 8 and 26 isoquinoline alkaloids were characterized using GC-QTOF-MS and RP-UHPLC-DAD-QTOFMS, respectively, and they belonged to the following subclasses: protoberberine, protopine, aporphine, benzophenanthridine, spirobenzylisoquinoline, morphinandienone, and benzylisoquinoline. Moreover, the latter analytical method was selected to determine at $280 \mathrm{~nm}$ the concentration of protopine $(9.6 \pm 0.7 \mathrm{mg} / \mathrm{g})$, a potential active compound of the extract. In conclusion, although GC-MS has been commonly used for the analysis of this type of phytochemicals, RP-UHPLC-DAD-QTOF-MS provided essential complementary information. This analytical method can be applied for the quality control of phytopharmaceuticals containing Fumaria extracts currently found in the market.
\end{abstract}

\section{Introduction}

In the "Conspiracy of Cortes" the Spanish novelist Matilde Asensi mentions the usage of Fumaria as a natural treatment for bubonic plague [1]. This fact is not far from fiction since the genus Fumaria (Fumarioideae, Papaveraceae) has traditionally been used in traditional medicine [2]. This genus consists of above 46 species widespread in the world, which grows in wheat fields, plains, and low hills in Europe, Middle East, South Asia, and so on [3]. The biological activities of Fumaria spp. are linked to the presence of key compounds such as isoquinoline alkaloids [4]. In fact, alkaloids, including the aforementioned type, have recently been reviewed to be effective treatments of intestinal inflammation injury in animal models [5]. Interestingly, recent studies have shown the low toxicity 
of a Fumaria capreolata alkaloid extract (white rampingfumatory) in vitro and in vivo [2], as well as their intestinal anti-inflammatory effects in mice colitis [6] and antinociceptive activity [7].

Isoquinoline alkaloids derive from the amino acid tyrosine, after its conversion to 3,4-dihydroxyphenylethylamine (dopamine) and 4-hydroxyphenylacetaldehyde that act as intermediary molecules [8]. This type of alkaloids has been characterized by thin layer chromatography [9], gas chromatography (GC) coupled to flame ionization detector (FID) [10], and mass spectrometry (MS) [11-14], as well as liquid chromatography (LC) coupled to UV/Vis, diode array detection (DAD) [15], and mass spectrometry (MS) [16]. In the case of GC-MS, there is available standard mass spectral data library for the characterization of several phytochemical classes, but it is not at all complete for alkaloids in comparison with other phytochemicals and explained by their relatively poor volatilization [17]. In the case of LCMS, there are efforts to generate spectral libraries using different MS analyzers and collision energies due to the little lack of consistency, standardization, or reproducibility as compared with GC-MS or nuclear magnetic resonance spectroscopy [18]. MassBank (http://www.massbank.jp/) and Metlin (https://metlin.scripps.edu/) are examples of public repositories of tandem mass spectral data.

Recent studies have demonstrated the potential of the hybrid mass analyzer quadrupole-time-of-flight (QTOF) for the profiling of hundreds of natural plant metabolites. This type of mass analyzers provides excellent selectivity and mass accuracy over a wide dynamic range and elucidates the molecular formula of unknown compounds. It also performs tandem MS, which is useful for a preliminary structural elucidation [19-21] when information in databases is limited. Thus, the objective of this study was to explore the potential of GC and LC coupled to QTOF mass analyzer for the profiling of isoquinoline alkaloids in F. capreolata. This plant was selected due to its aforesaid biological properties. In addition, to the best of our knowledge, there are not any reports in the literature accomplishing the comparison of these two analytical platforms for the qualitative characterization of this type of phytochemicals.

\section{Experimental}

2.1. Preparation of the Alkaloid Extract. Aerial parts of F. capreolata were collected from Bejaia area (Algeria) in May 2012, when they were at the flowering and fruit setting stage. Plants were authenticated by Dr. F. Maiza-Benabdesselam (Laboratory of Plant Biotechnology and Ethnobotany, University of Bejaia, Algeria) and voucher specimen was deposited (Reference number FC015). Aerial parts of the plants were dried in oven at $40^{\circ} \mathrm{C}$ overnight and ground. In brief, the powder samples were extracted as described before $[2,7]$ with methanol and dichloromethane to afford a crude extract of alkaloids. For analysis, the alkaloid extract $(10 \mathrm{mg})$ was dissolved in methanol $(1 \mathrm{~mL})$ (ThermoFisher, Waltham, MA, USA) and filtered with a $0.20 \mu \mathrm{m}$ syringe filter of polytetrafluoroethylene $(13 \mathrm{~mm})$ (ThermoFisher).
2.2. Analysis by GC-QTOF-MS. Analyses were carried out using an Agilent technologies (Palo Alto, CA, USA) gas chromatography (GC) system 7890B (G3440B) coupled to a 7200 accurate mass quadrupole-time-of-flight (Q-TOF) mass spectrometer. A capillary column was employed: HP-5MS (5\% phenyl 95\% dimethylpolysiloxane, $30 \mathrm{~m} \times 0.250 \mathrm{~mm}$ i.d.; $0.25 \mu \mathrm{m}$ film thickness). The column temperature was initially held at $200^{\circ} \mathrm{C}$ for $1 \mathrm{~min}$, increased at $25^{\circ} \mathrm{C} / \mathrm{min}$ to $250^{\circ} \mathrm{C}$, and then held at $250^{\circ} \mathrm{C}$ for $31 \mathrm{~min}$. Finally, a ramp of $10^{\circ} \mathrm{C} / \mathrm{min}$ was applied until $310^{\circ} \mathrm{C}$ and maintained for $5 \mathrm{~min}$. The total run was $45 \mathrm{~min}$. The helium flow rate was $1.2 \mathrm{~mL} / \mathrm{min}$. The injection program included sequential washing steps of the syringe and a sample pumping step for removal of small air bubbles. The injection was $1 \mu \mathrm{L}$ using a programmable PAL GC sampler 120 and with a split ratio of $10: 1$. The inlet and the transfer line temperatures were $250^{\circ} \mathrm{C}$ and $300^{\circ} \mathrm{C}$, respectively. The ion source was electron impact (EI) carried out at $70 \mathrm{eV}$ and the temperature was $250^{\circ} \mathrm{C}$. The mass range from $\mathrm{m} / z 125$ to 700 was scanned at a rate of 3 scans/s. The TOF analyzer was calibrated previously to each analysis using an Agilent calibration tune mix.

\subsection{Analysis by Reversed-Phase Ultrahigh Performance Liquid} Chromatography Coupled to Diode Array Detection (DAD) and QTOF-MS. Analyses were made with an Agilent 1200 series rapid resolution (Palo Alto, CA, USA) equipped with a binary pump, an autosampler, and a DAD. The mobile phases consisted of a water with $0.2 \%$ formic acid (mobile phase A) and acetonitrile (mobile phase B), and a multistep linear gradient was applied: $0-5.5 \mathrm{~min}, 1-7 \% \mathrm{~B} ; 5.5-11 \mathrm{~min}$, $7-14 \% \mathrm{~B} ; 11-17.5 \mathrm{~min}, 14-24 \% \mathrm{~B} ; 17.5-22.5 \mathrm{~min}, 24-40 \%$ B; $22.5-27.5 \mathrm{~min}, 40-100 \% \mathrm{~B}$; $27.5-28.5 \mathrm{~min}, 100-100 \% \mathrm{~B}$; $28.5-29.5 \mathrm{~min}, 100-1 \% \mathrm{~B}$. The latter value (99\% $\mathrm{A}$ and $1 \%$ B) was held for $5.5 \mathrm{~min}$ to equilibrate the column with the initial conditions prior to the next injection. The total run was $35 \mathrm{~min}$. The flow rate was set at $0.5 \mathrm{~mL} / \mathrm{min}$ throughout the gradient. Separation was carried out with a Zorbax Eclipse XDB-C18 column $(4.6 \times 50 \mathrm{~mm}, 1.8 \mu \mathrm{m}$ of particle size $)$ (Agilent) at $25^{\circ} \mathrm{C}$. The UV-Vis spectra were recorded from 190 to $600 \mathrm{~nm}$, and a wavelength channel of $280 \pm 4 \mathrm{~nm}$ was applied for quantitative purposes. The injection volume was $1 \mu \mathrm{L}$.

The spectra were acquired in negative and positive ion modes over a mass-to-charge $(\mathrm{m} / \mathrm{z})$ range from 70 to 1500 . The operation conditions were set in the adequate polarity as follows: gas temperature: $325^{\circ} \mathrm{C}$; drying gas: nitrogen at $10 \mathrm{~L} / \mathrm{min}$; nebulizer pressure: 20 psig; sheath gas temperature: $400^{\circ} \mathrm{C}$; sheath gas flow: nitrogen at $12 \mathrm{~L} / \mathrm{min}$; capillary voltage: $4000 \mathrm{~V}$; skimmer: $45 \mathrm{~V}$; octapole radiofrequency voltage: $750 \mathrm{~V}$; focusing voltage: $500 \mathrm{~V}$, with the corresponding polarity automatically set. The acquisition mode was AutoMS2.

Internal mass correction of each sample was performed with a continuous infusion of Agilent TOF mixture containing two mass references for each ionization mode. In the positive ionization mode, the two reference mass ions were at $m / z 121.0509$ (purine) and 922.0098 (hexakis $(1 \mathrm{H}$, $1 \mathrm{H}, 3 \mathrm{H}$-tetrafluoropropoxy) phosphazine). Alternatively, in the negative ionization mode trifluoroacetic acid ammonium salt $(\mathrm{m} / z 112.9856$ that is trifluoroacetic acid) and hexakis 
$(1 \mathrm{H}, 1 \mathrm{H}, 3 \mathrm{H}$-tetrafluoropropoxy) phosphazine $(\mathrm{m} / z 1033.9881$ corresponding to the trifluoroacetic acid ammonium salt adduct) were used. The detection window was set to $100 \mathrm{ppm}$. Data acquisition $(2.5 \mathrm{~Hz})$ in the profile mode was governed via the Agilent MassHunter Workstation B.05.01.

Data analysis was performed on a Mass Hunter Qualitative Analysis B.06.00, as commented before. The isotope model selected was "common organic molecules" with a peak spacing tolerance of $\mathrm{m} / z 0.0025$ and $7 \mathrm{ppm}$.

All analyses by GC-QTOF-MS and RP-HPLC-DADQTOF-MS were done in triplicate.

2.4. Data Processing. Data analysis was performed on MassHunter Qualitative Analysis B.06.00 (Agilent technologies). The characterization of compounds was performed by generation of candidate formula with a mass accuracy limit of $5 \mathrm{ppm}$ for the analysis of RP-UHPLC-DAD-QTOF-MS and $10 \mathrm{ppm}$ for GC-QTOF-MS, and also considering the MS score that should be close to 100 . The latter parameter is related to the contribution to mass accuracy, isotope abundance, and isotope spacing for the generated molecular formulae. Using GC-QTOF-MS, alkaloids were characterized by direct comparison of their fragmentation pattern with data from the NIST MS library (NIST11.L) and NIST chemistry WebBook (http://webbook.nist.gov/chem- istry/) when possible, as well as literature about Papaveraceae. In the case of RP-UHPLC-DAD-QTOF-MS and -MS/MS, MassBank and Metlin were consulted. Moreover, chemical structure information was also retrieved from SciFinder Scholar (https://scifinder.cas.org), Reaxys (http://www.reaxys.com), and KNApSAcK Core System (http://kanaya.naist .jp/knapsack_jsp/top.html).

2.5. Quality Control of Protopine. Protopine hydrochloride stock solution was conveniently diluted with methanol to prepare calibration points $(8-260 \mathrm{nmol} / \mathrm{mL})$. The external standard method was used and a linear regression for the calibration curve was estimated using the area under the curve of protopine against concentration. Repeatability was assayed by three consecutive injections of the methanolic solutions of at three levels three times (intraday repeatability) and five times on two different days (interday repeatability) [22]. The limit of detection (LOD) and quantification (LOQ) were estimated as protopine concentration giving a signal equal to the blank signal plus three and ten standard deviations of the blanks, respectively [23].

\section{Results and Discussion}

3.1. Alkaloidal Profiling via GC-TOF-MS. Briefly, for the untargeted analysis of the alkaloidal extract via GC-TOFMS the strategy followed consisted of the generation of the molecular formulae of the detected ions in the chromatographic profile (Figure 1(a)) and studying the fragmentation pattern using NIST MS library when possible or based on literature $[11,12,14,24]$. The results provided by the GC-TOF-MS analyzer are given in Table 1, which shows MS experimental data, retention time (RT), and main fragments generated by EI from F. capreolata alkaloids. Table S1 (in Supplementary Material available online at https://doi.org/10.1155/2017/5178729) additionally provides literature about their occurrence in $F$. capreolata, fragmentation pattern in GC-MS, and information found in databases. Using this approach, a total of eight isoquinoline alkaloids were characterized and eluted in the following order: stylopine, protopine, cheilanthifoline, isoboldine, coreximine, dihydrosanguinarine, fumariline, and parfumine. These alkaloids were representatives of protoberberine, protopine, benzophenanthridine, aporphine, and spirobenzylisoquinoline types. These results agreed with previous studies on this plant using GC coupled to a quadrupole mass analyzer [11, 12] and other studies $[9,25]$, while additionally we also detect coreximine. Moreover, in agreement with previous studies $[13,14,17,24]$ our results suggest that the stationary phase $5 \%$ phenyl 95\% dimethyl polysiloxane is also an adequate alternative to the more apolar stationary phases consisting of $100 \%$ dimethyl polysiloxane, which is also commonly used for the separation of isoquinoline alkaloids [11, 12].

EI source is considered a hard ionization method since it provokes extensive fragmentation by high energetic electrons. Interestingly, the TOF mass analyzer enabled us to detect the molecule ions $\left(\mathrm{M}^{+}\right)$of each alkaloid in itself and generate their molecular formulae with errors lower than $10 \mathrm{ppm}$ (Table 1 and Table S1). It seems that this platform is highly attractive since it can provide not only the fragmentation pattern of alkaloids, but also their molecular formulae, a basic clue for structure elucidation of unknown compounds that are not available in current GC-MS libraries. This was the case of dihydrosanguinarine and parfumine (Table S1), whose structures were proposed based on both their molecular formula and the fragmentation pattern that could be fortunately compared with literature $[11,14,24]$.

As an example of the strategy followed, Figure 2 shows the fragmentation pattern of stylopine, protopine, and fumariline using GC-QTOF-MS.

3.2. Alkaloidal Profiling via RP-HPLC-DAD-QTOF-MS. Preliminary $F$. capreolata alkaloids were studied using ESI in both negative and positive ionization modes. The second ionization mode led to a richer and complex chromatographic profile (Figure S1) with more intense signals. Thus, it was selected for further studies. This is not surprising since most LC-MS methods have applied the latter ionization mode for the analysis of alkaloids. As an example, the alkaloid profile of F. capreolata is shown in Figure 1(b). It depicts the base peak chromatogram (BPC) under the selected analytical conditions, as well as the chromatograms at $280 \mathrm{~nm}$, at which isoquinoline alkaloids show absorption, and $450 \mathrm{~nm}$, which is particular of quaternary protoberberine alkaloids.

Afterwards, using this analytical platform, the characterization of the alkaloids was based on the following strategy described in our previous studies on other plant phytochemicals [20]. Firstly, the UV-Vis spectra and the generation of the molecular formulae enabled proposing the chemical structures of the alkaloids. For that, literature on Fumaria spp. $[9,11,12,25,26]$ and the aforementioned chemical databases were consulted. Secondly, the MS/MS spectra were studied 


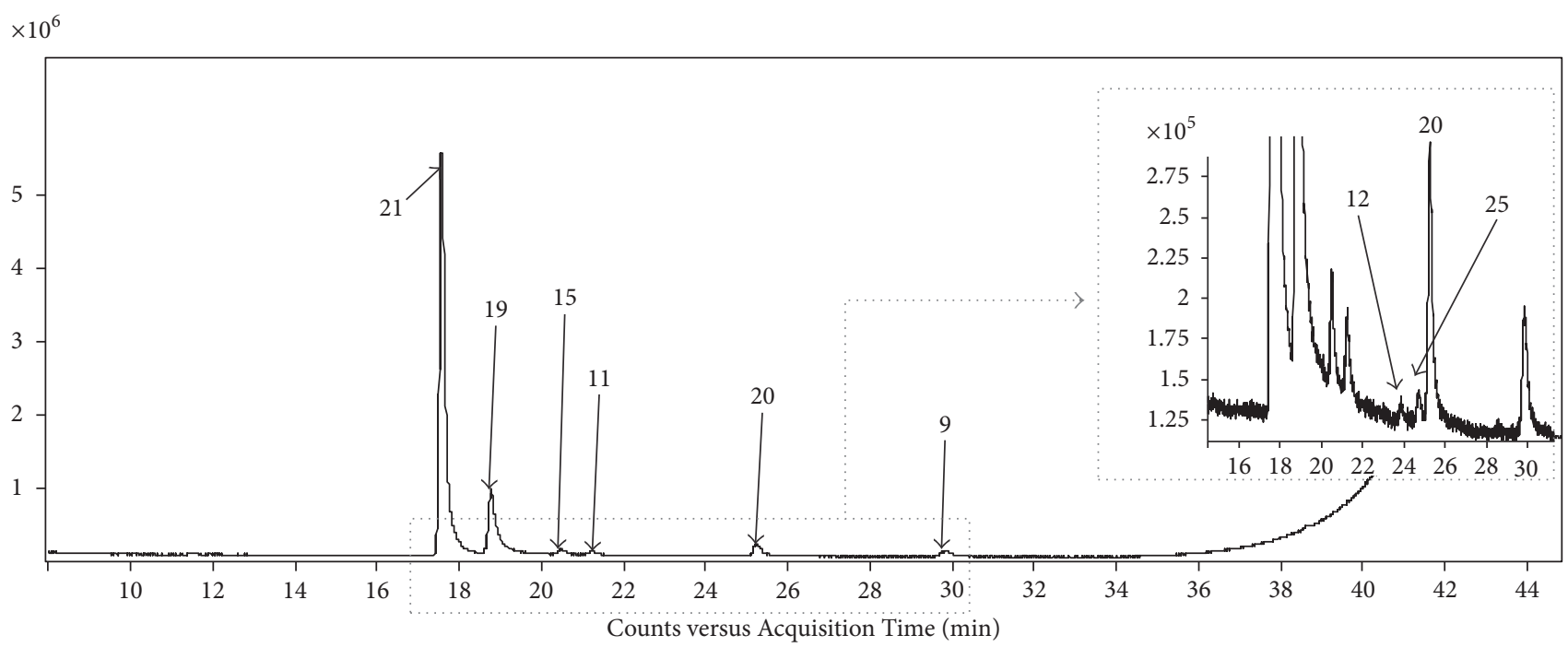

(a)

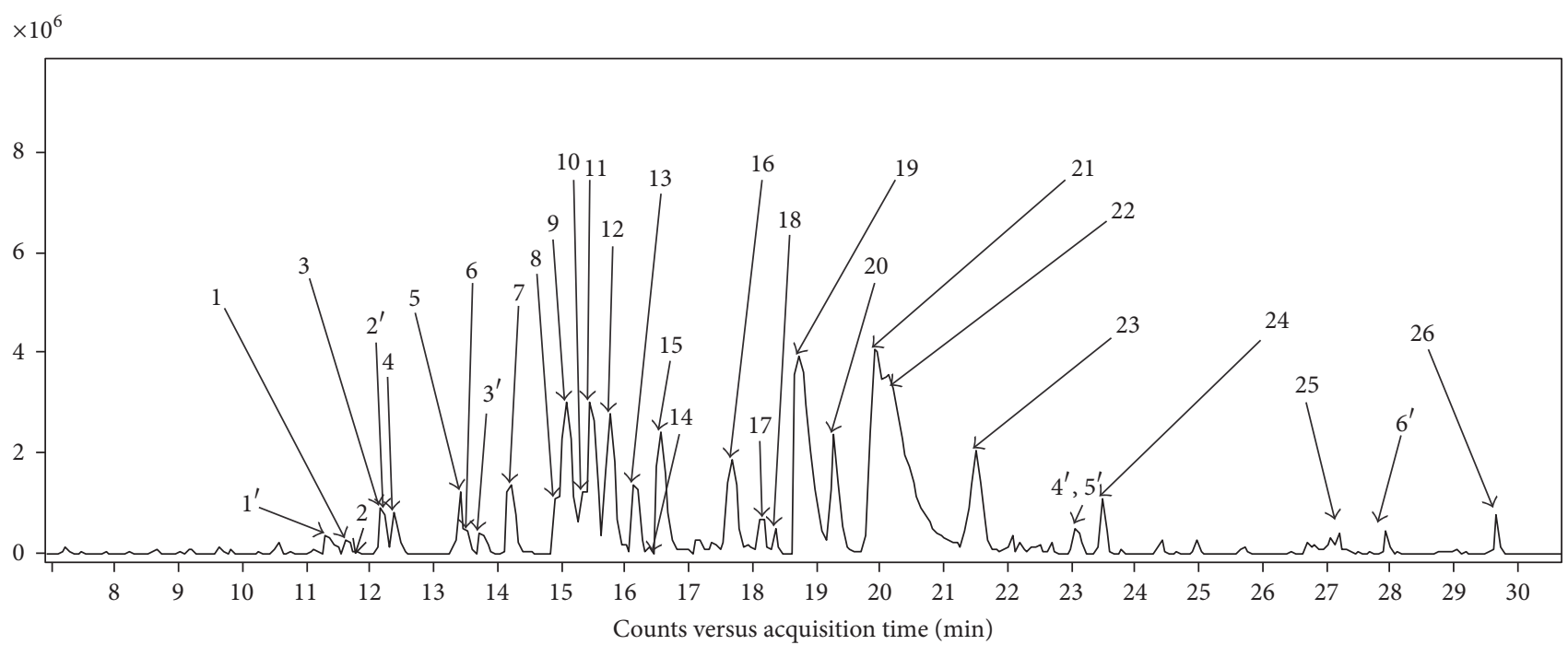

(b)

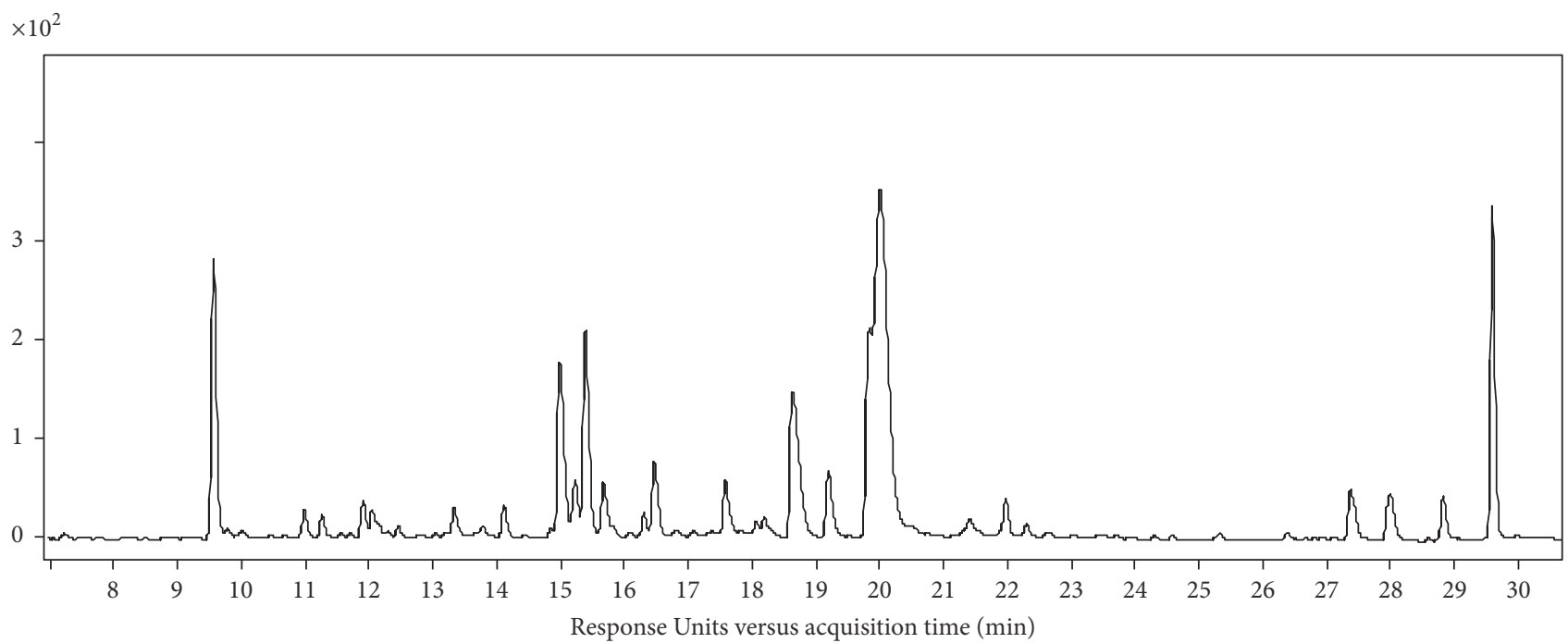

(c)

Figure 1: Continued. 


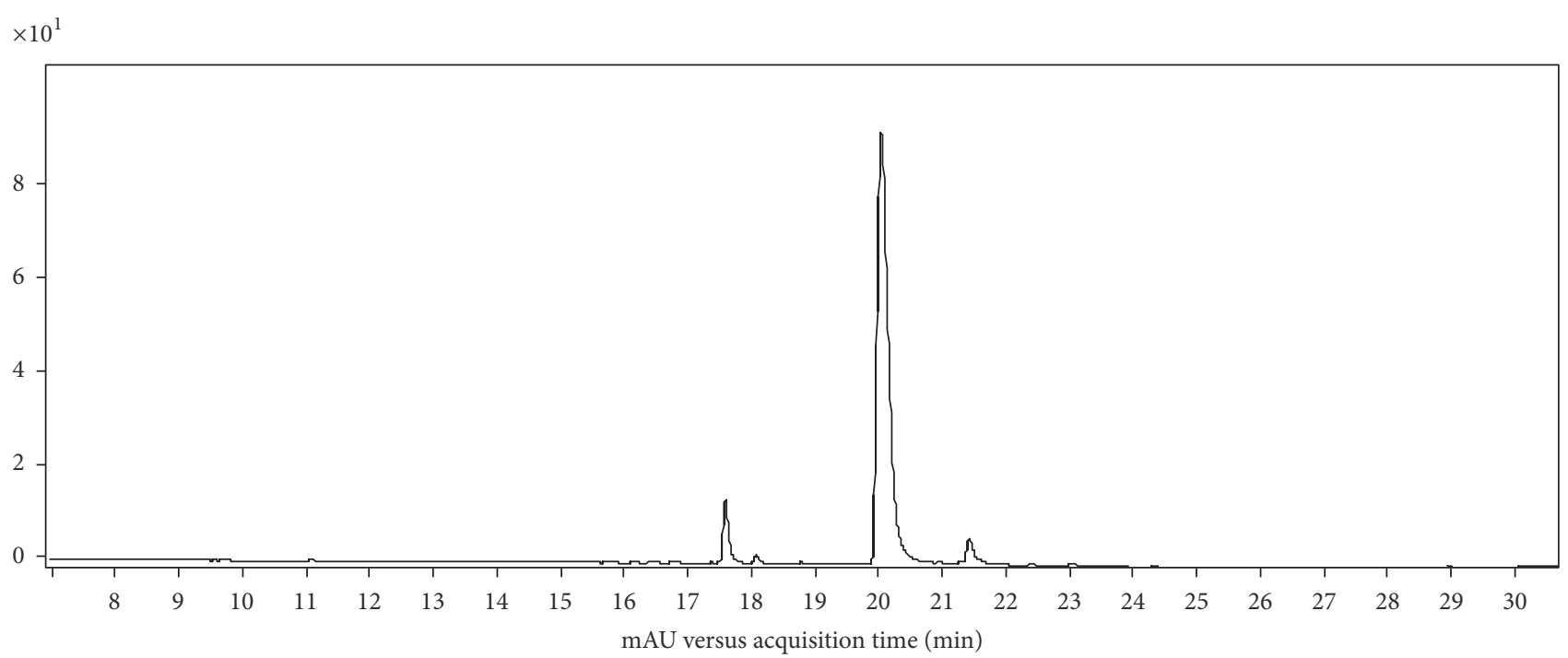

(d)

FIgURE 1: (a) Total ion chromatogram obtained by GC-QTOF-MS, (b) base peak chromatogram in the positive ionization mode, (c) chromatograms at $280 \mathrm{~nm}$, and (d) $450 \mathrm{~nm}$ of the alkaloid extract obtained by RP-UHPLC-DAD-QTOF-MS. Compounds are numbered according to Table 2: (1) pallidine; (2) isoboldine derivative; (3) N,N-dimethylcoclaurine (4) fumaritine; (5) coclaurine; (6) Nmethylcoclaurine; (7) magnoflorine; (8) reticuline; (9) parfumine; (10) parfumidine; (11) isoboldine; (12) coreximine; (13) methylcoreximine 1; (14) methylcoreximine 2; (15) cheilanthifoline; (16) dehydrocheilanthifoline; (17) demethyleneberberine/jatrorubine; (18) cryptopine; (19) protopine; (20) fumariline; (21) stylopine; (22) coptisine; (23) corysamine; (24) impatien C; (25) dihydrosanguinarine; (26) 8-oxocoptisine. $1^{\prime}-6$ unknown compounds.

in depth. In this way, 26 alkaloids were characterized on the basis of their spectrometric data and the results are shown in Table 2 and Table S2: RT, molecular formula, observed $\mathrm{m} / z$, mass error, MS score, UV-Vis maximums, and main MS/MS fragments. As before, Table S2 includes additional information. The chemical structures are depicted in Figure 3.

Using the positive ionization mode, the tertiary alkaloids led $[\mathrm{M}+\mathrm{H}]^{+}$ions, whereas quaternary alkaloids yielded $[\mathrm{M}]^{+}$ ions in the mass spectra that is in accordance with Ding et al. [27]. Moreover, the different types of alkaloids showed different UV absorption spectra with maximum absorption between 260 and $290 \mathrm{~nm}$ (Table 2 and Table S2). Interestingly, UV-Vis spectroscopy is particularly useful for the elucidation of quaternary isoquinoline alkaloids. For example, UV absorption spectra of quaternary protoberberine alkaloids, $16,17,22$, and 23 , are determined by the auxochromic groups bound to ring $\mathrm{D}$ with a minimum at $301-310 \mathrm{~nm}$, indicating a protoberberine core with substituents on carbons $\mathrm{C} 9$ and $\mathrm{C} 10$ [28] and also presented a characteristic maximum absorption around $450 \mathrm{~nm}$, in agreement with Grycováa et al. [29]. As an example, see coptisine in Figures 3 and 4.

Once the molecular formulae were generated and the UVVis results contrasted, the MS/MS fragmentation patterns were studied and compared with those in databases, but only experimental MS/MS spectra of protopine and cryptopine were found (Table S2). However, most of the MS/MS spectra shared common ions with those found in studies on plants containing alkaloids from Papaveraceae, Lauraceae, and Rutaceae [27, 30-35] being useful to define the chemical structure of the alkaloids. As an example, Figure 4 shows the fragmentation pattern of isoboldine, protopine, coptisine, and stylopine (tetrahydrocoptisine), as examples of aporphine, protopine, and both protoberberine quaternary and tertiary alkaloids, respectively. The fragmentation patterns of isoboldine and coptisine were characterized by a cleavage of the substituted groups of the alkaloid core, whereas no ring fusion was observed. In this sense, isoboldine $(\mathrm{m} / z$ 328) shows the primary loss of $\mathrm{CH}_{3} \mathrm{NH}_{2}(31 \mathrm{Da})$ at $\mathrm{m} / z 297$ due to the presence of a methyl substituent in the amino group, as it was observed for its derivative $(\mathrm{m} / \mathrm{z} 314)$ at $\mathrm{m} / z 283$. This is a characteristic of this type of aporphine alkaloids [36]. Afterwards, the loss of $\mathrm{CH}_{3}, \mathrm{CH}_{3}, \mathrm{OH}, \mathrm{CH}_{3} \mathrm{OH}$, and $\mathrm{CO}$ occurred. In the case of protopine, their product ions were generated by dehydration $(\mathrm{m} / \mathrm{z} 336)$, retro-Diels-Alder fragmentation $(\mathrm{m} / \mathrm{z} 149$ and 206), and subsequent losses of $\mathrm{H}_{2} \mathrm{O}(\mathrm{m} / z$ 188) and $\mathrm{OH}(\mathrm{m} / z$ 189), in accordance with Shim et al. [37] and Schmidt et al. [30]. The fragmentation of the protopine backbone was also observed by GC-QTOFMS as it was shown in Figure 2. Similarly, the fragmentation of the backbone of stylopine generated fragment ions at $\mathrm{m} / z 176$ and 149, which were the most abundant. These ion fragments were also observed in the MS/MS spectrum of the compound $24\left(\mathrm{~m} / z 396, \mathrm{C}_{22} \mathrm{H}_{21} \mathrm{NO}_{6}\right)$ (Table 2), together with the fragment at $\mathrm{m} / z 322$ released after the primarily neutral loss of a substituent with molecular formula $\mathrm{C}_{3} \mathrm{H}_{6} \mathrm{O}_{2}$ $(74 \mathrm{Da})$. Therefore, this compound was tentatively identified as impatien $\mathrm{C}$, a protoberberine recently characterized in Corydalis impatiens (Fumarioideae, Papaveraceae) [38].

Dihydrosanguinarine (benzophenanthridine type) was also characterized by the fragmentation of their substituents, 


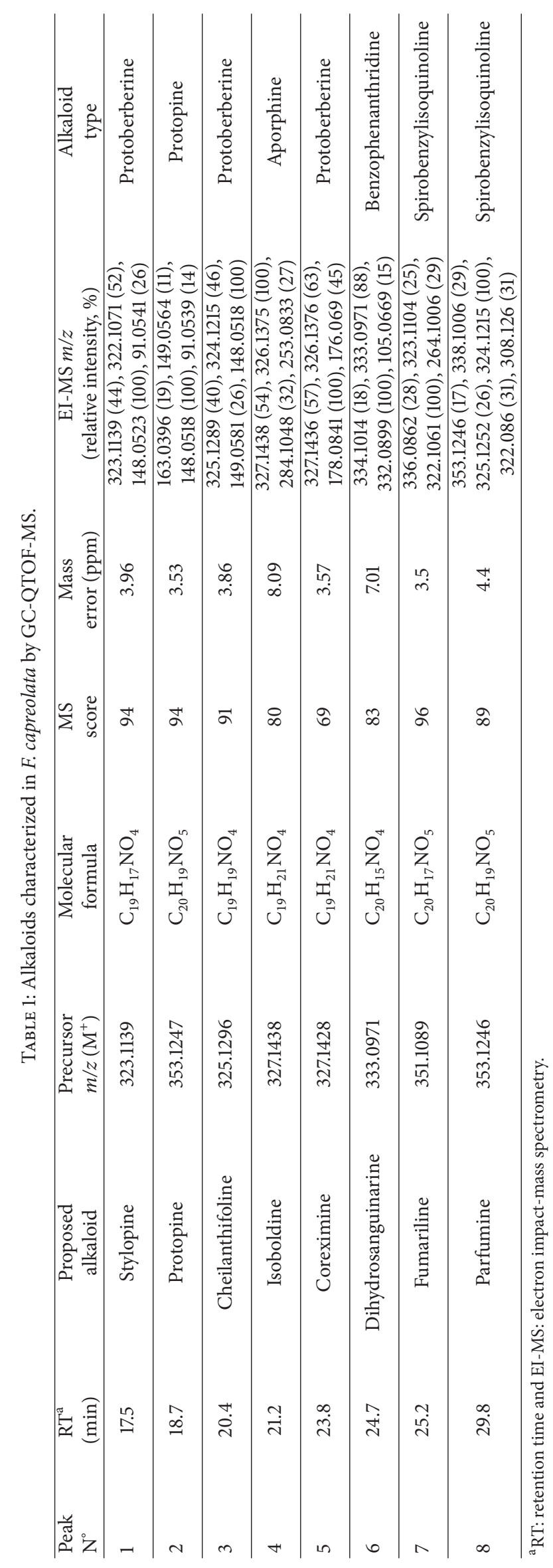




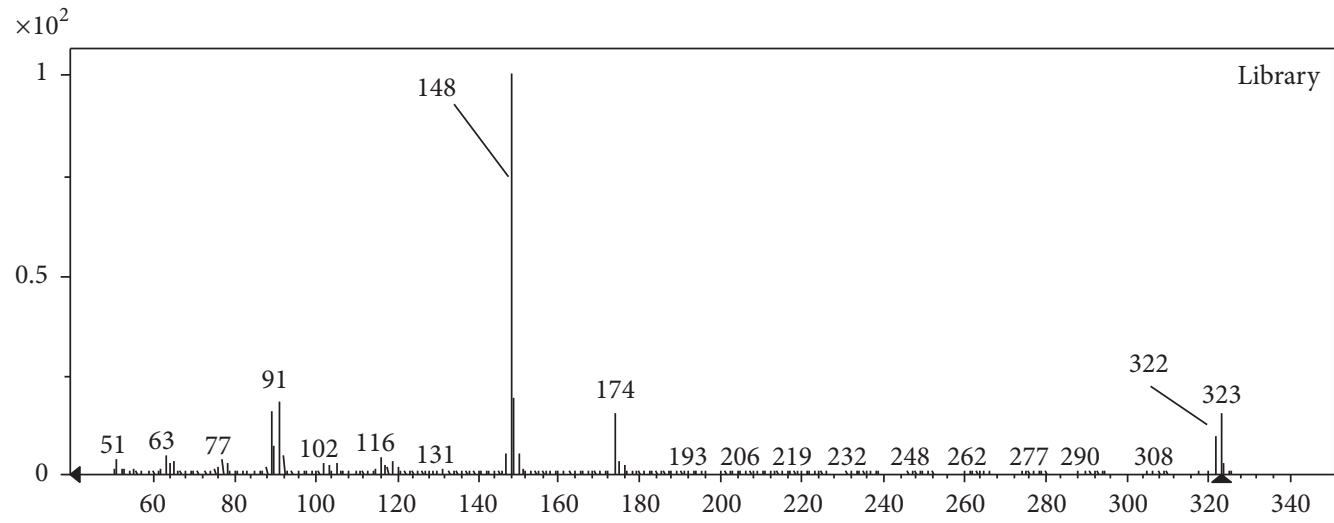

(a)

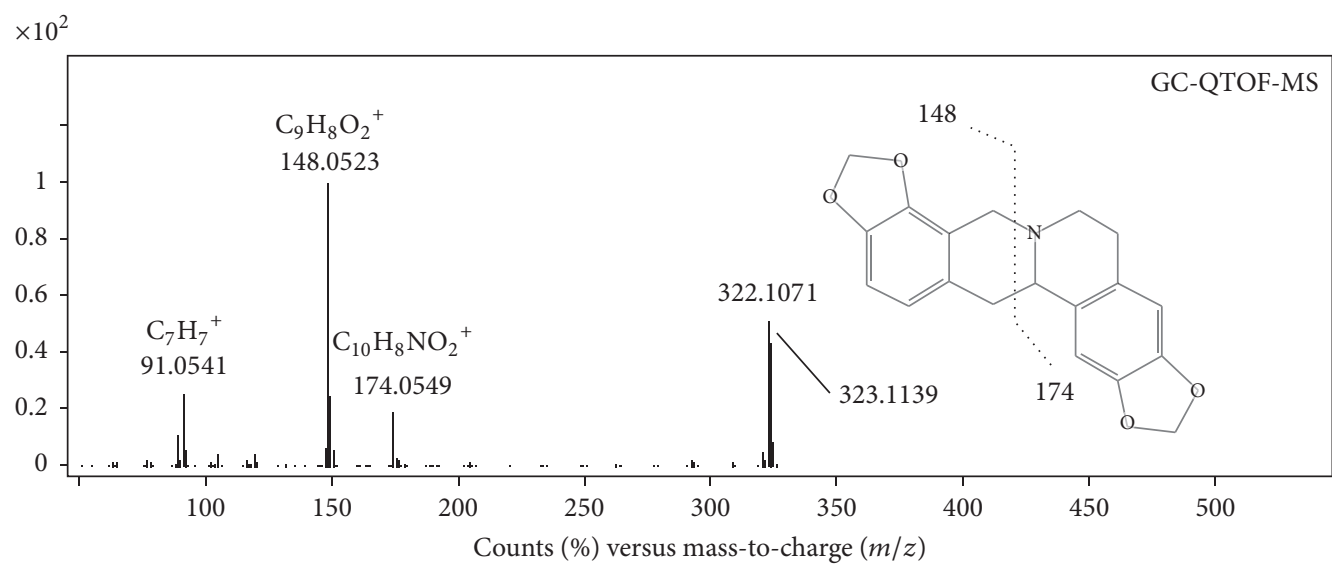

(b)

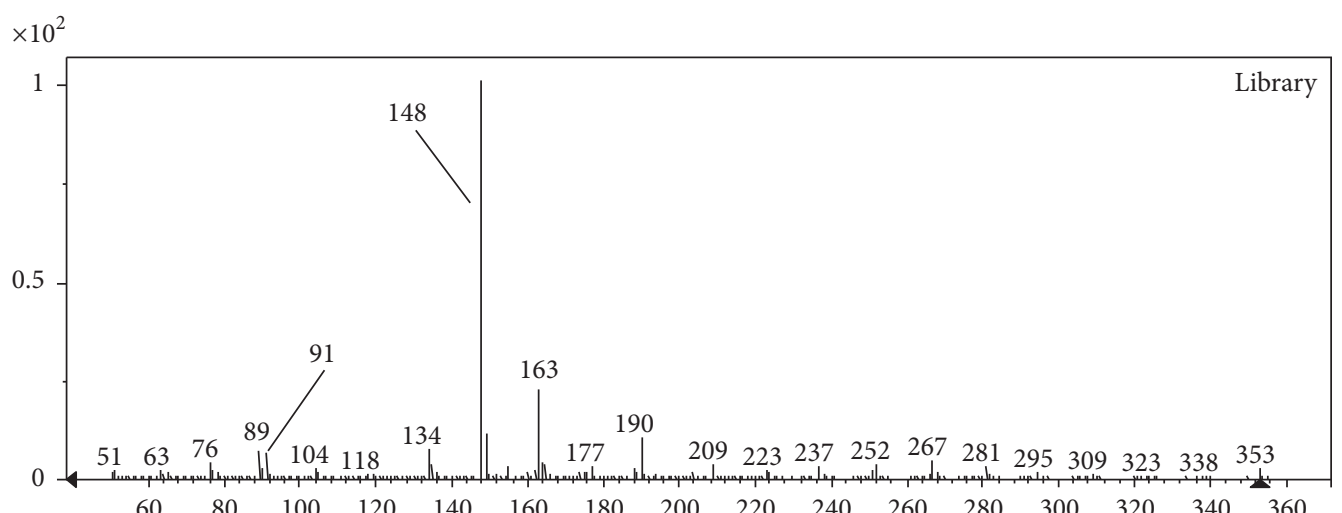

(c)

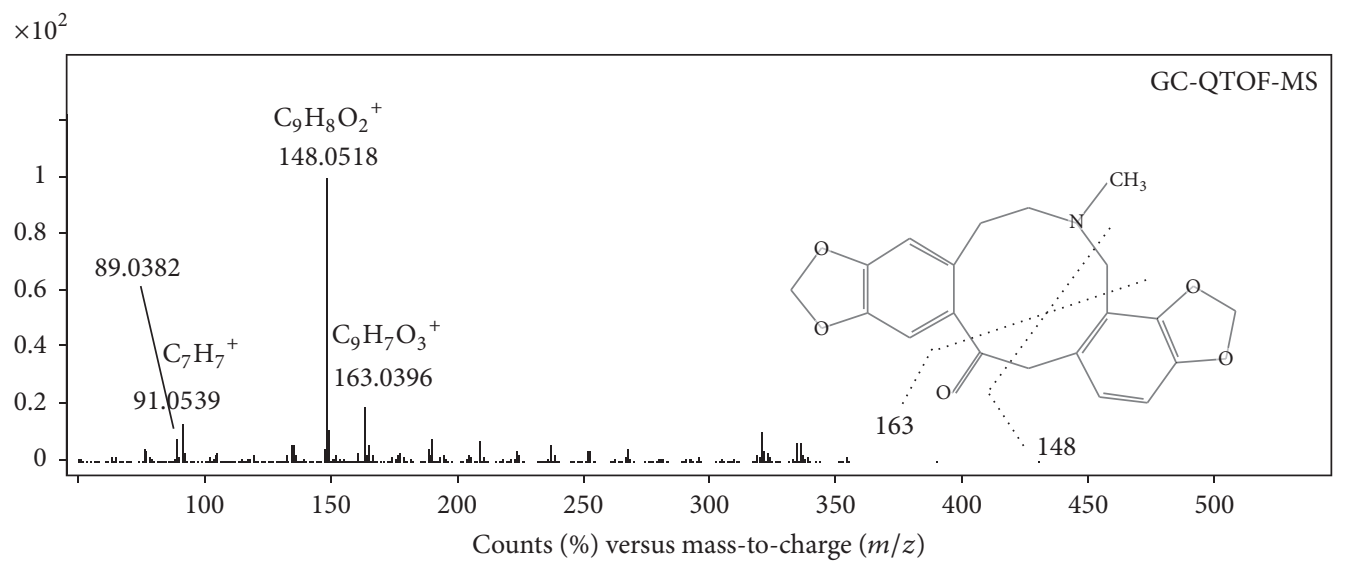

(d)

Figure 2: Continued. 


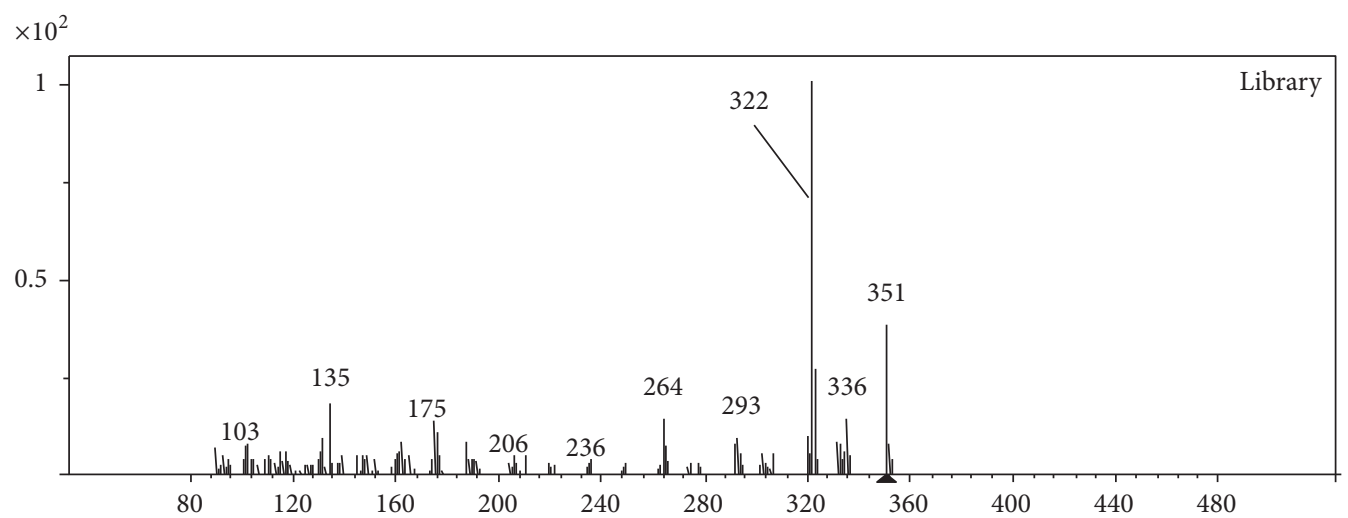

(e)

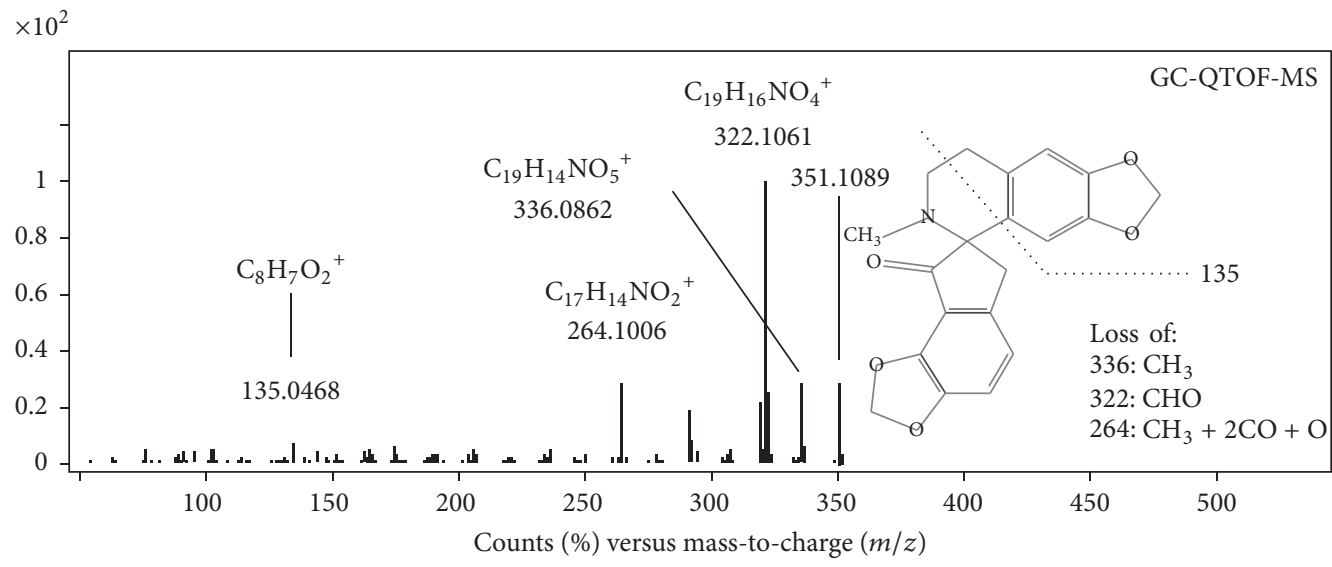

(f)

FIGURE 2: Fragmentation patterns of stylopine ((a) and (b)), protopine ((c) and (d)), and fumariline ((e) and (f)) described in the library and determined by GC-QTOF-MS, respectively.

being the most abundant ions formed by the loss of $\mathrm{CH}_{3}$ $(m / z 319), \mathrm{CH}_{2} \mathrm{O}(\mathrm{m} / z$ 304), and $\mathrm{CO}(\mathrm{m} / z$ 276) (Table 2). Benzylisoquinolines presented the loss of $\mathrm{NH}_{3}$ (coclaurine), $\mathrm{CH}_{3} \mathrm{NH}_{2}$ (N-methylcoclaurine), or $\mathrm{C}_{2} \mathrm{H}_{6} \mathrm{NH}(\mathrm{N}, \mathrm{N}$ dimethylcoclaurine) at $m / z 269$, substituents of the isoquinoline core, and also shared a common ion at $m / z 107\left(\mathrm{C}_{7} \mathrm{H}_{7} \mathrm{O}^{+}\right)$, which correspond to the methylphenol moiety generated by inductive cleavage [37]. Finally, spirobenzylisoquinolines showed not only the neutral loss of substituents of the alkaloid core but also the breakage at the isoquinoline core generating ions at $m / z 177\left(\mathrm{C}_{10} \mathrm{H}_{11} \mathrm{NO}_{2}\right)$ (fumariline), $179\left(\mathrm{C}_{10} \mathrm{H}_{13} \mathrm{NO}_{2}\right)$ (parfumidine), and $193\left(\mathrm{C}_{11} \mathrm{H}_{15} \mathrm{NO}_{2}\right)$ (parfumine), and its subsequent fragmentation (e.g., $m / z 135$ and 137).

3.3. Comparison of the QTOF Platforms. Figure 5 represents a comparative plot of the results described above. All the isoquinoline alkaloids found by GC-TOF-MS in the extract of $F$. capreolata were also detected using RP-HPLC-DAD-QTOFMS. More polar alkaloids, such as quaternary alkaloids, were not detected by the first analytical platform probably due to their poor volatility that is its major drawback [17]. Moreover, the use of RP-HPLC-DAD-QTOF-MS enables us to find some alkaloids, which were not reported in this plant by other authors (e.g., compounds 2, 3, 5, 10, 13, 14, 17, 23, 24, and 26). This can be explained by the fact that most of the studies on Fumaria spp. used GC-MS for studying their alkaloids profile.

A recent study has shown the trends of using ESI, EI, and matrix-assisted laser desorption/ionization (MALDI) as ionization sources for natural products investigations; the application of ESI source is continuously growing, while MALDI and EI remain constant [39]. This trend possibly reflects the huge expansion of ESI applications in this area explained by the fact that MS is a versatile detection system and ESI source enables the analysis of a wide range of chemical structures, as our results revealed.

3.4. Quantification of Protopine. Protopine exhibits antiinflammatory activity both in vitro and in vivo [40, 41]. This alkaloid can contribute, at least in part, to explaining the antinociceptive and anti-inflammatory effects of the $F$. capreolata extract showed in our previous studies $[2,6,7]$. Thus, for the quality control of this alkaloid extract, protopine was preliminary selected as analytical/active marker since it is also commercially available and the RP-HPLC method was selected since it was shorter than the GC method. Moreover, the quantification of this compound was 


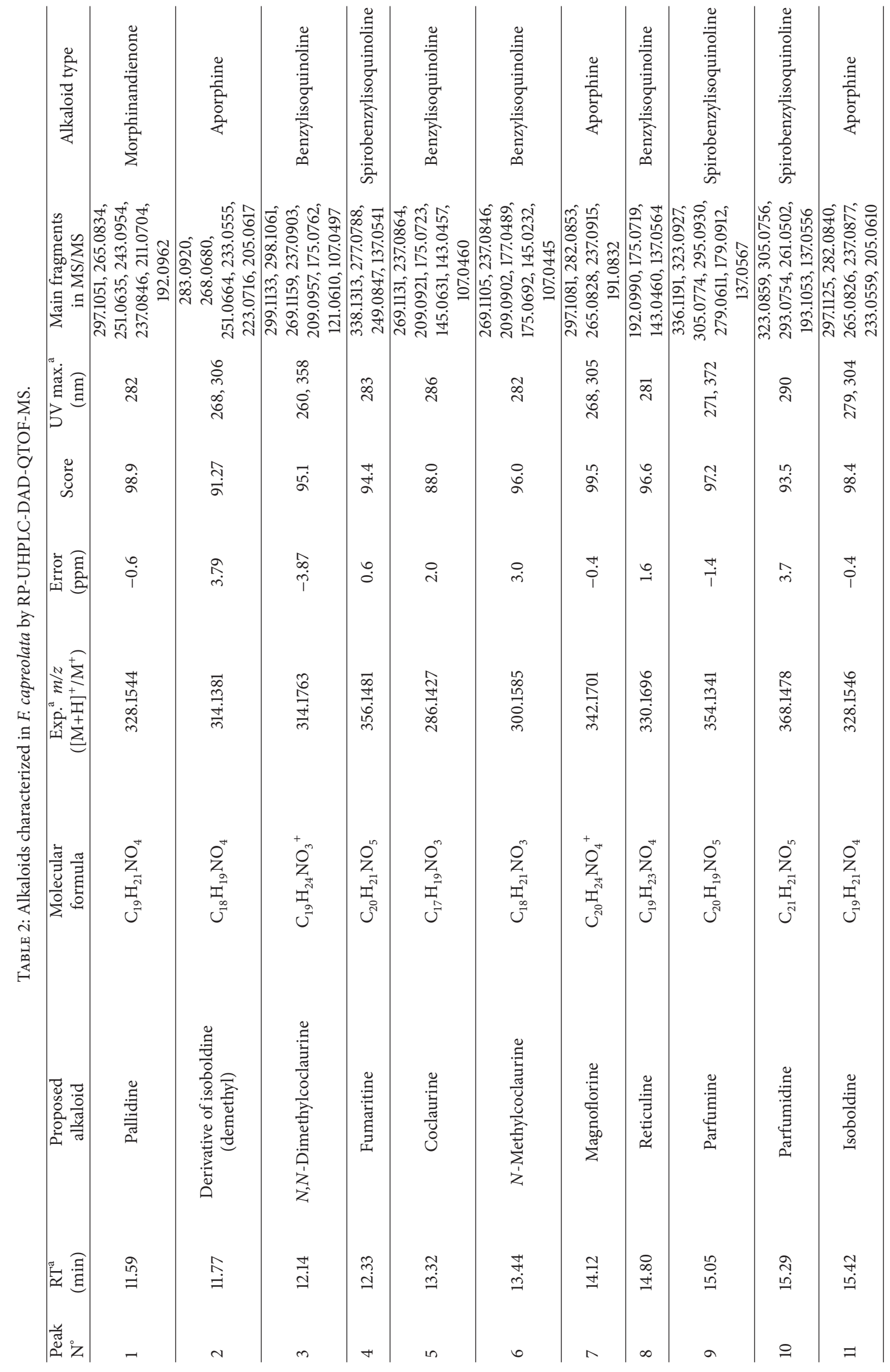




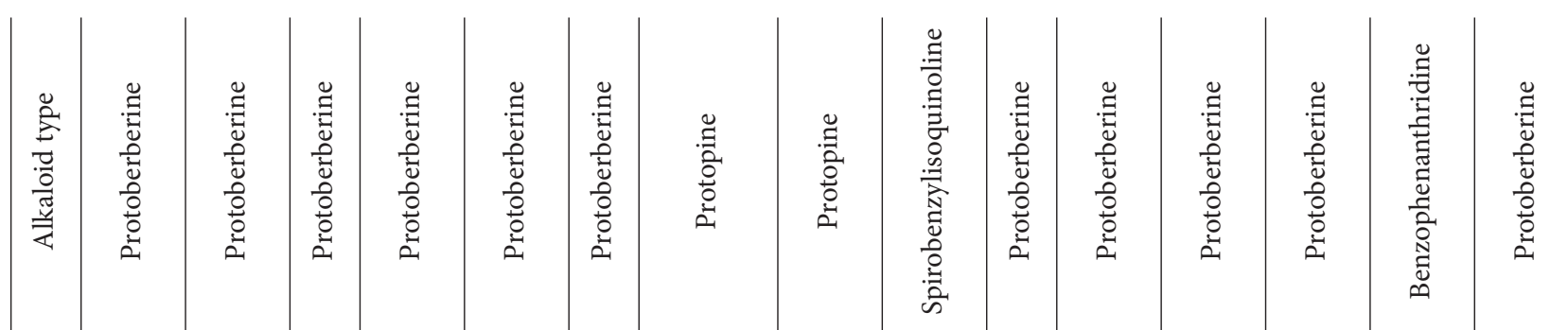

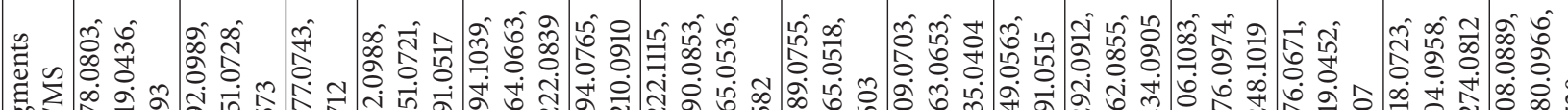

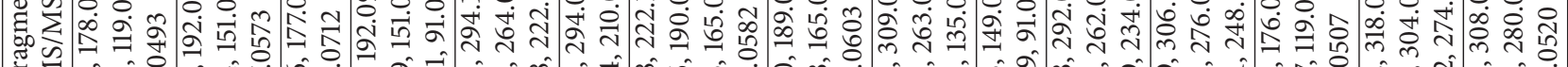

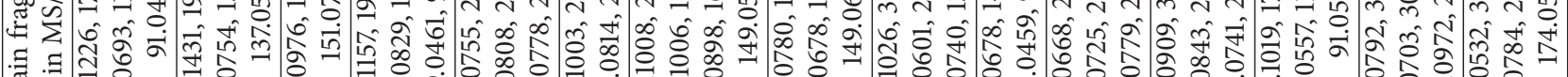

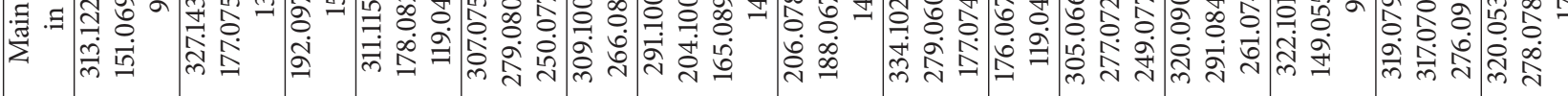

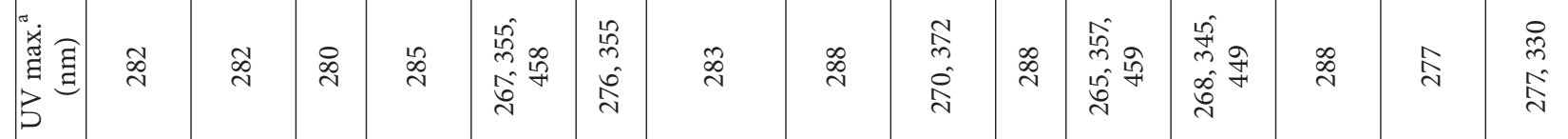

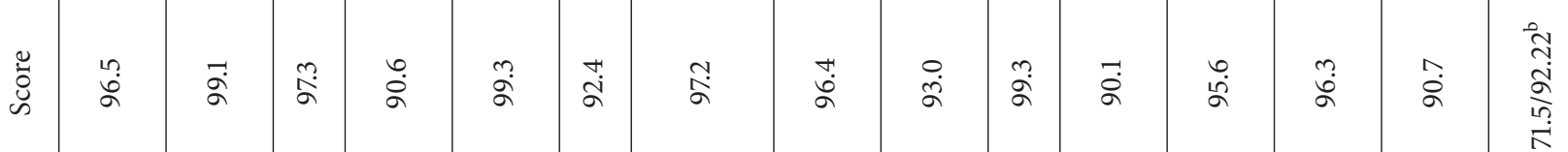

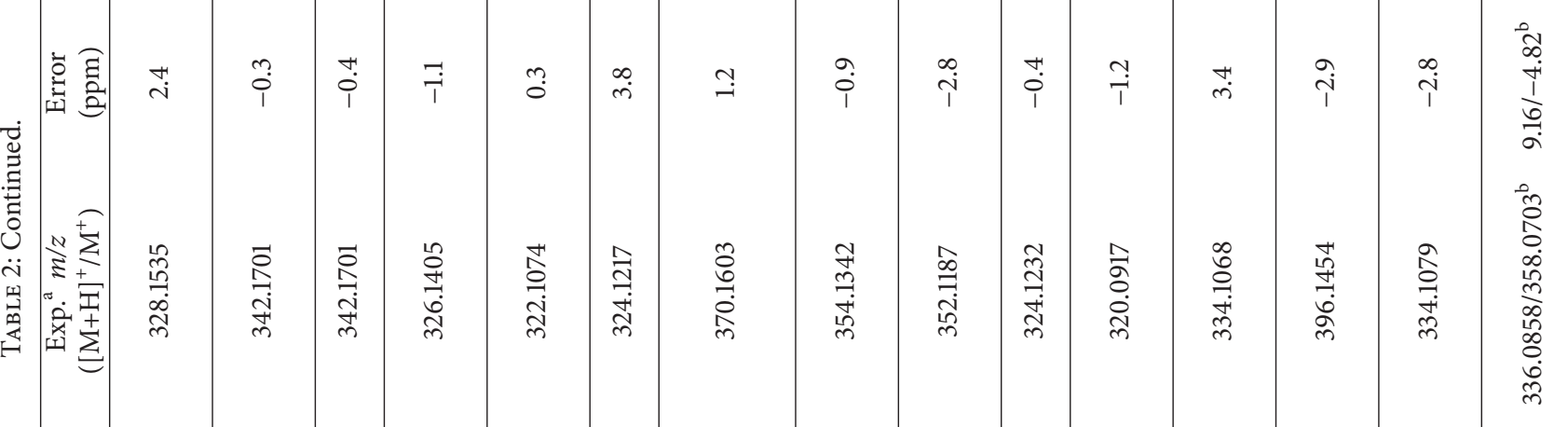

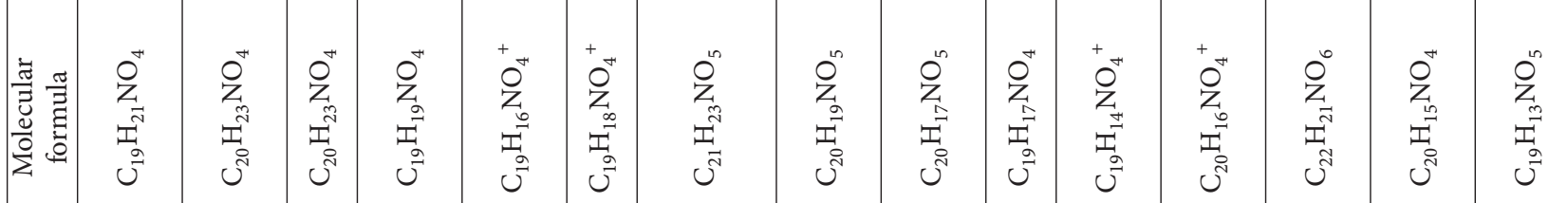

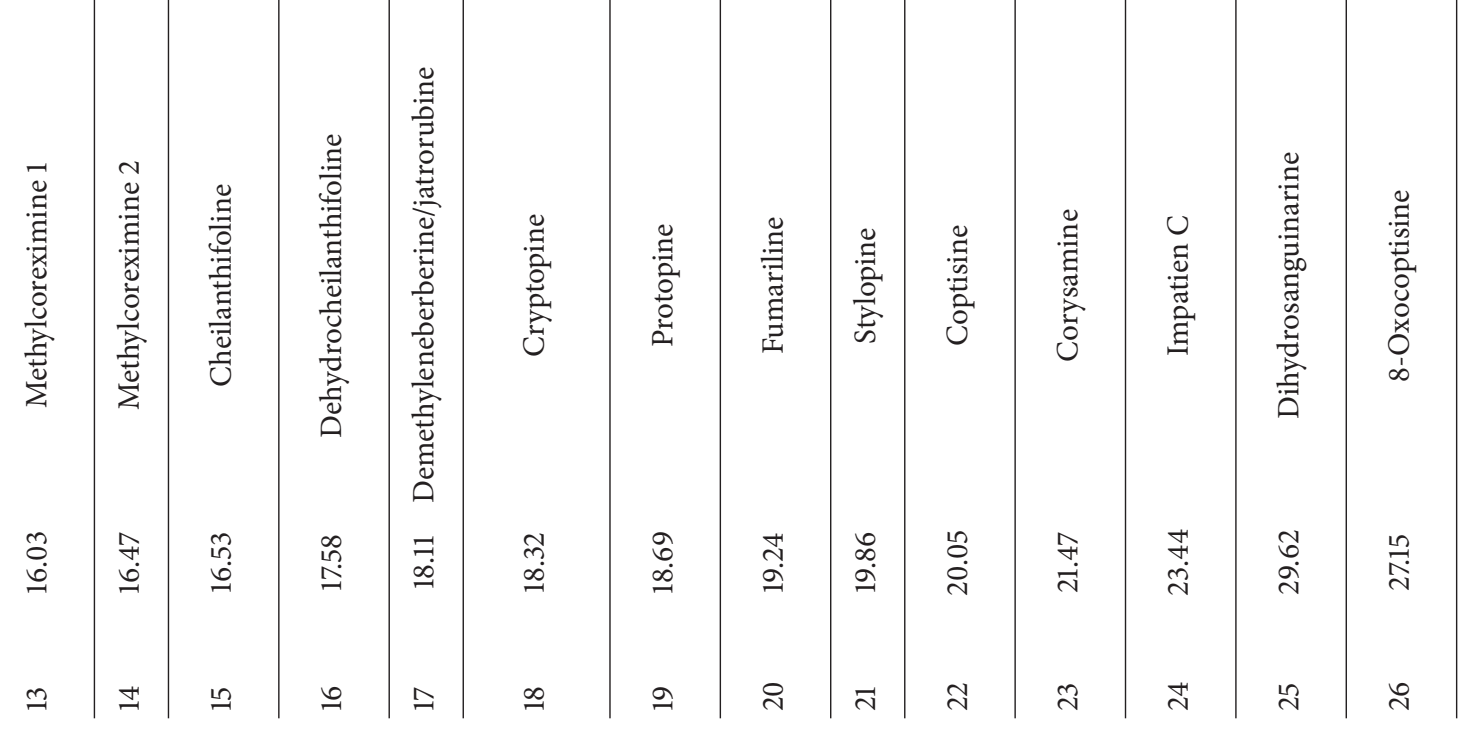




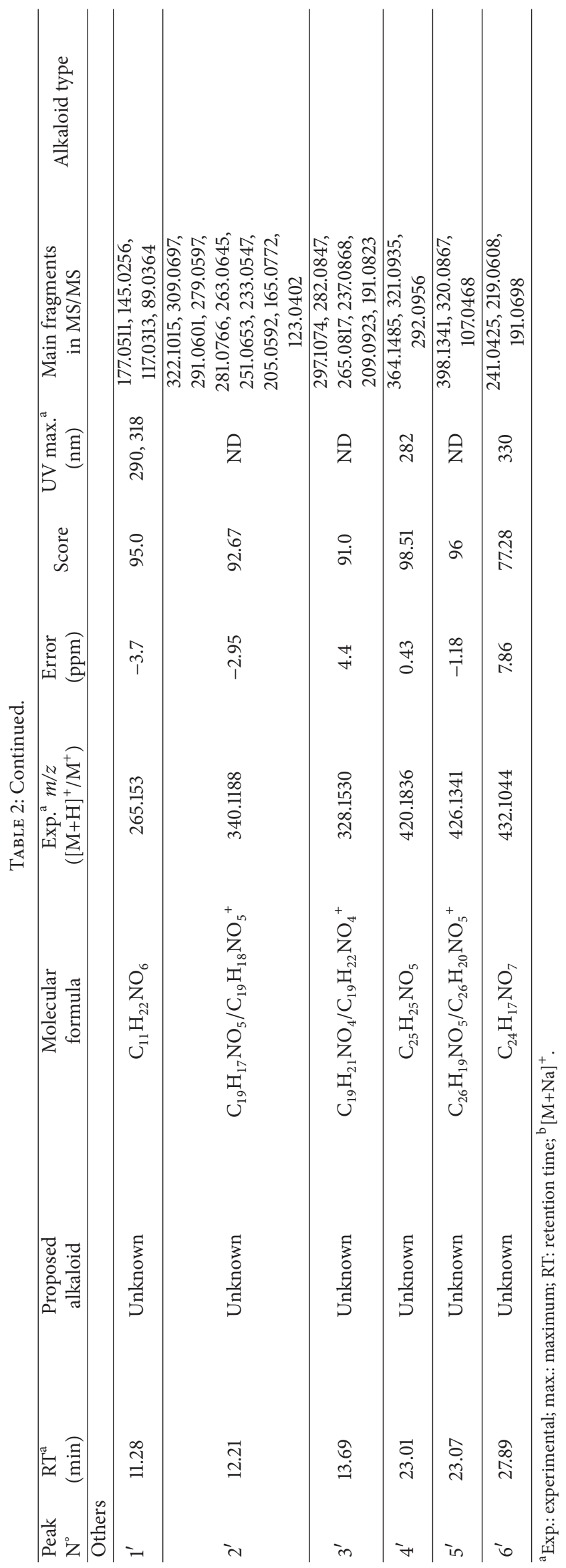




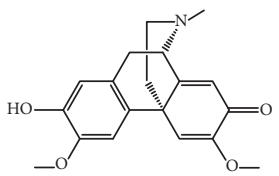

(1) Pallidine

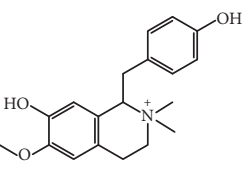

(3) N,N-Dimethylcoclaurine

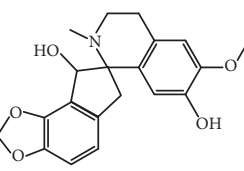

(4) Fumaritine

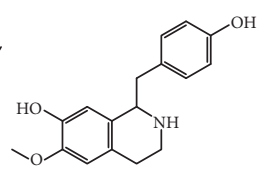

(5) Coclaurine

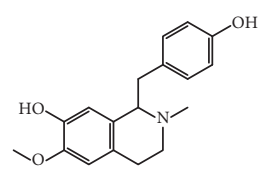

(6) N-Methylcoclaurine<smiles>COc1ccc2c(c1O)-c1c(O)c(OC)cc3c1[N+](C)(CC2)CC3</smiles>

(7) Magnoflorine

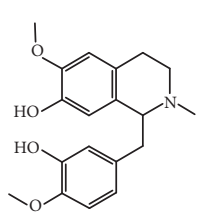

(8) Reticuline

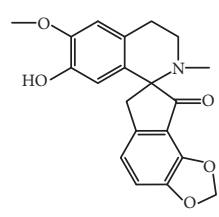

(9) Parfumine

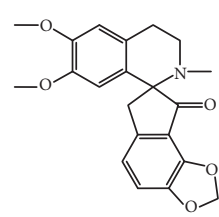

(10) Parfumidine

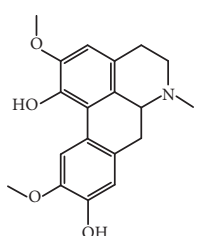

(11) Isoboldine<smiles>COc1cc2c(cc1O)C1Cc3cc(O)c(OC)cc3NCC1NC2</smiles>
of isoboldine

(15) Cheilanthifoline<smiles>COC1CC2CCC3=CC4CCC5CCC5C4CC3CC2CC1O</smiles>

(16) Dehydrocheilanthifoline

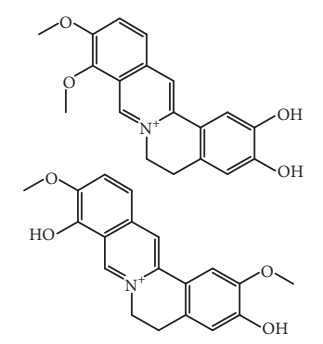

(17) Demethyleneberberine/jatrorubine

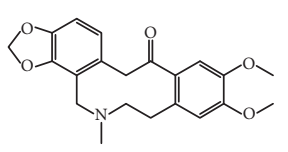

(18) Cryptopine<smiles>O=C(O)C1CCC2CC3CCOC3=CC2C2CC(C=CC3OCO3)C12</smiles>

(24) Impatien C<smiles>CN(CCc1ccc2c(c1)OCO2)CCc1cc2c(cc1CCO)OCO2</smiles>

(19) Protopine

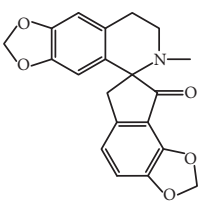

(20) Fumariline

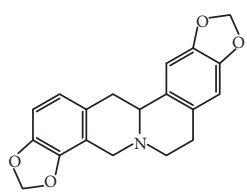

(21) Stylopine

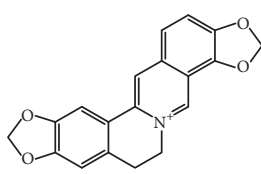

(22) Coptisine

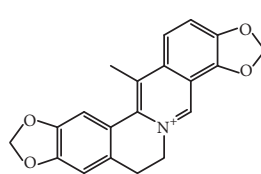

(23) Corysamine<smiles>CN1Cc2c(ccc3c2OCO3)-c2ccc3cc4c(cc3c21)OCO4</smiles><smiles>O=C1c2c(ccc3c2OCO3)CC2c3cc4c(cc3CCN12)OCO4</smiles>

(25) Dihydrosanguinarine

(26) 8-Oxocoptisine

FIGURE 3: Chemical structures of the alkaloids present in F. capreolata extract and characterized by the QTOF platforms. Compounds are numbered according to Table 2 .

performed at $280 \mathrm{~nm}$. This detector was selected since it is cheap and common in pharmaceutical/plant industries, which can be interested in reproducing the extraction protocol of isoquinoline alkaloids from F. capreolata or for further standardization purposes. The regression equation was $y=1.78 x+7.43$. A $R^{2}$ of 0.999 was obtained, indicating a good correlation. The repeatability met quality criteria, with relative standard deviation values lower than $10 \%$ and accuracy values close to $100 \%$, respectively [42] (Table S3). The LOD and LOQ were 0.2 and $6.6 \mathrm{nmol} / \mathrm{mL}$. Finally, using this method the estimated amount of protopine was $9.6 \pm$ $0.7 \mathrm{mg} / \mathrm{g}$.

The proposed analytical method can also be expanded for the quality control of phytopharmaceuticals containing Fumaria extracts, which can currently be found in the market without a detailed description of their active constituents.

\section{Conclusions}

GC and RP-UHPLC coupled to a high resolution QTOF mass analyzer are powerful analytical platforms for a quick structure determination of isoquinoline alkaloids, previously to the application of other spectroscopic tools. Although GCQTOF-MS provided structural information about 8 alkaloids, RP-HPLC-DAD-QTOF-MS gave a more exhaustive profiling of $F$. capreolata alkaloids (26 characterized compounds). The latter analytical method seems to be a requirement to detect quaternary alkaloids based on our results and previous literature about this plant. Moreover, novel alkaloids were characterized in this plant when using both methods, but this number was higher when using RP-UHPLC-DAD-QTOF-MS, such as a demethylated derivative of isoboldine, coclaurine, $\mathrm{N}, \mathrm{N}$-dimethylcoclaurine, and 8-oxocoptisine, among others. 

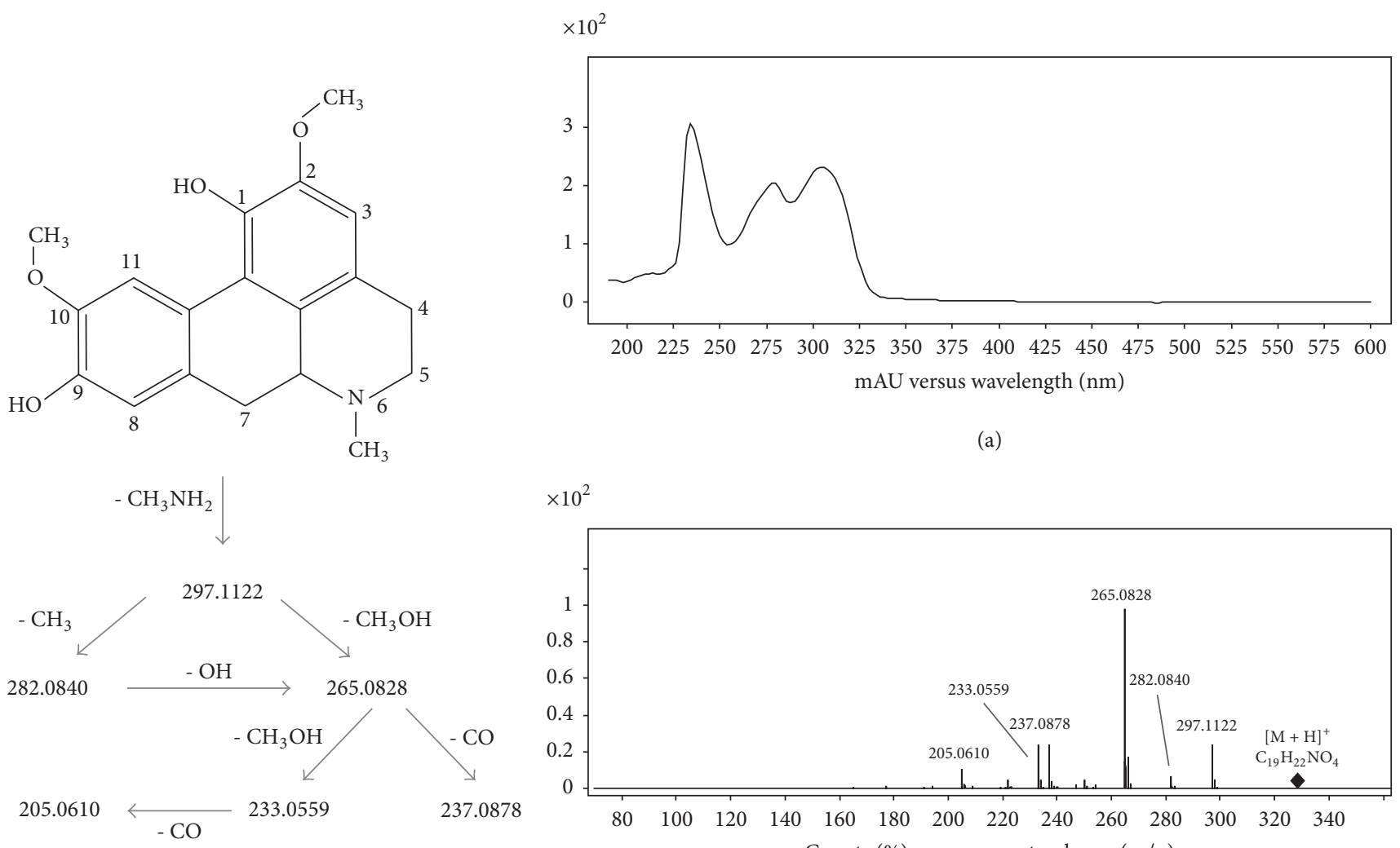

(a)

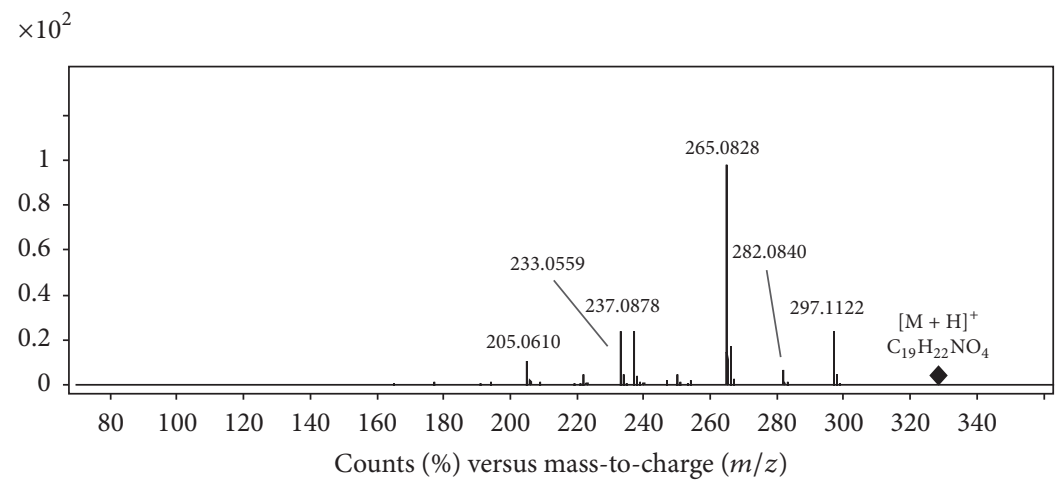

(b)
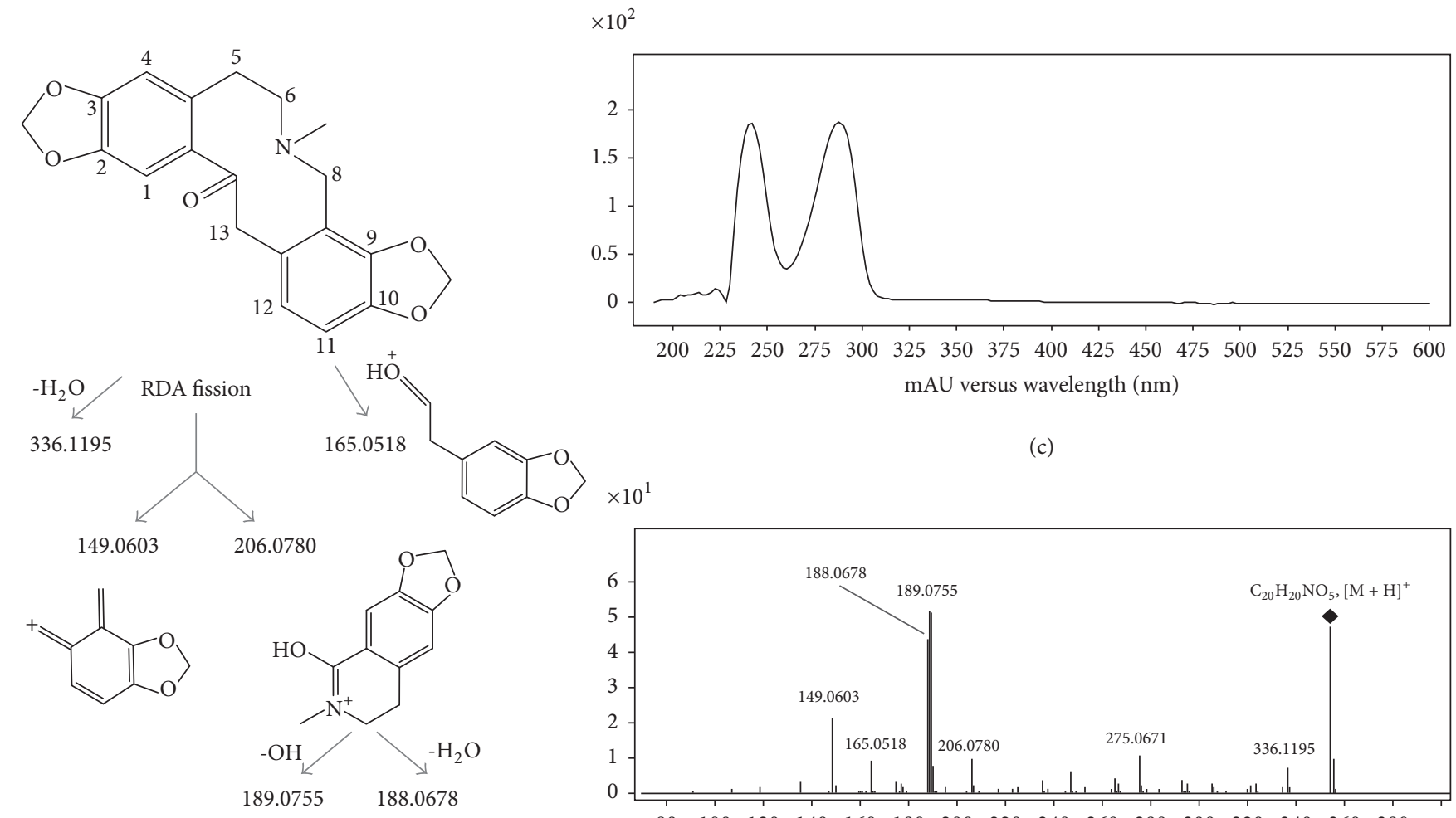

(c)

$\begin{array}{llllllllllllllll}80 & 100 & 120 & 140 & 160 & 180 & 200 & 220 & 240 & 260 & 280 & 300 & 320 & 340 & 360 & 380\end{array}$ Counts (\%) versus mass-to-charge $(\mathrm{m} / \mathrm{z}$ )

(d)

FIGURE 4: Continued. 

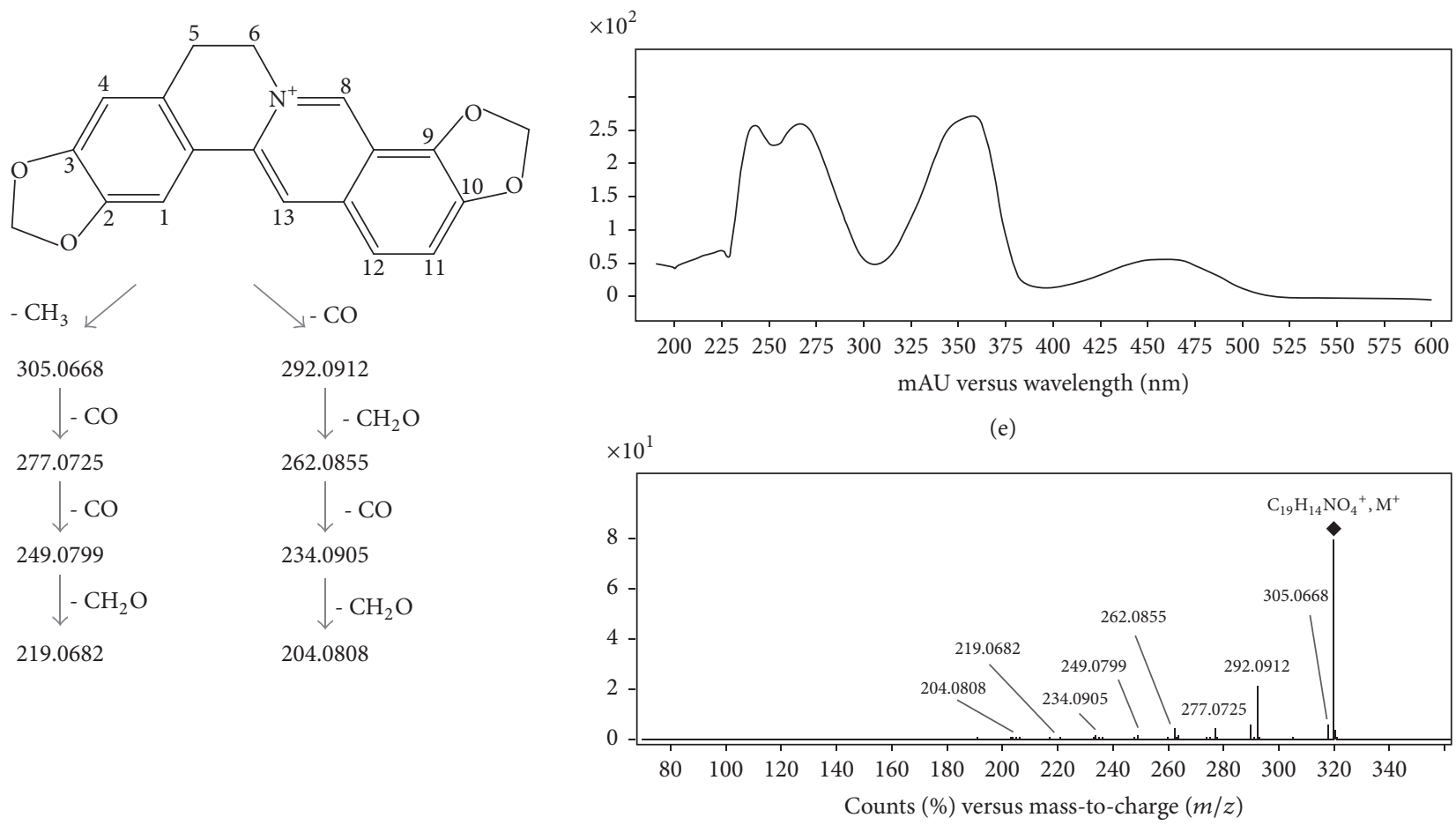

(f)

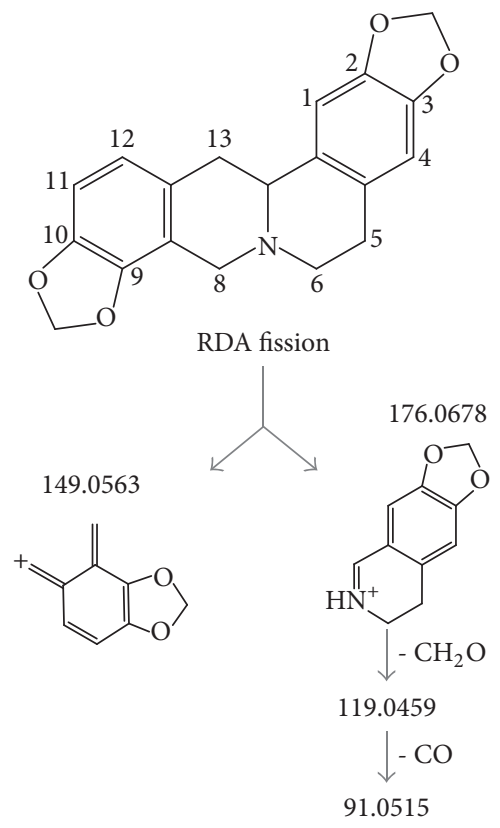

$\times 10^{2}$

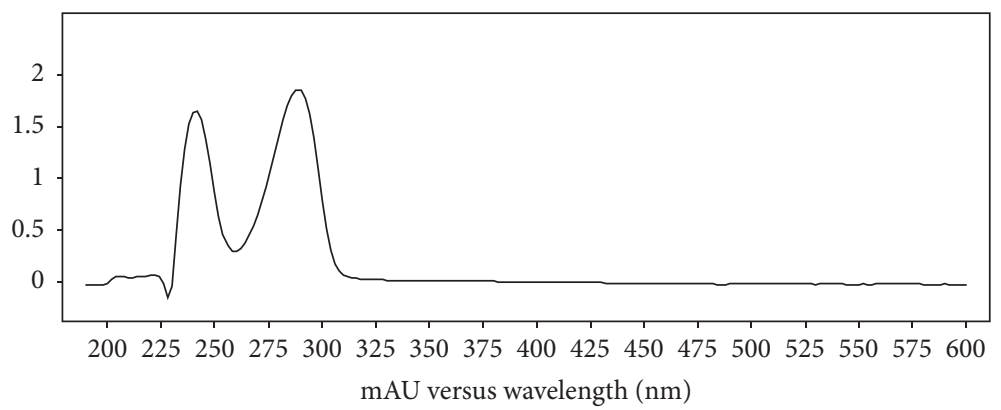

(g)

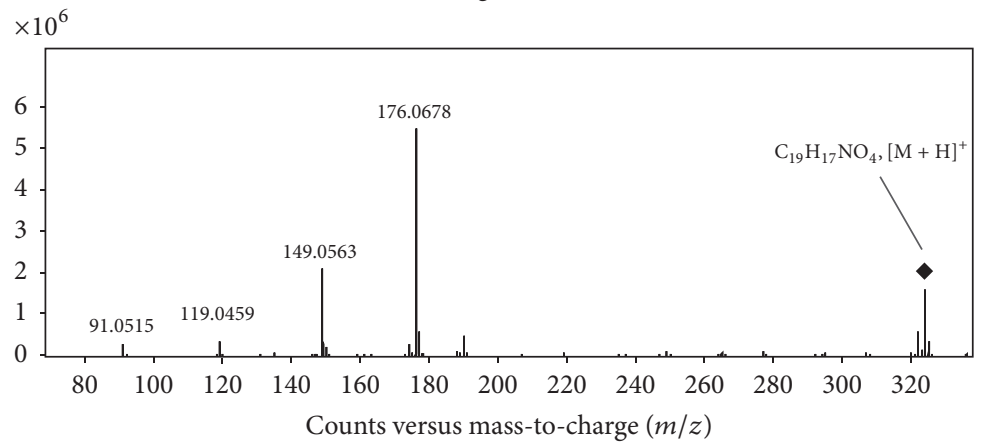

(h)

FIGURE 4: UV-Vis spectra and fragmentation pattern of isoboldine ((a) and (b)), protopine ((c) and (d)), coptisine ((e) and (f)), and stylopine $((\mathrm{g})$ and $(\mathrm{h}))$, respectively, determined by RP-UHPLC-DAD-QTOF-MS. 


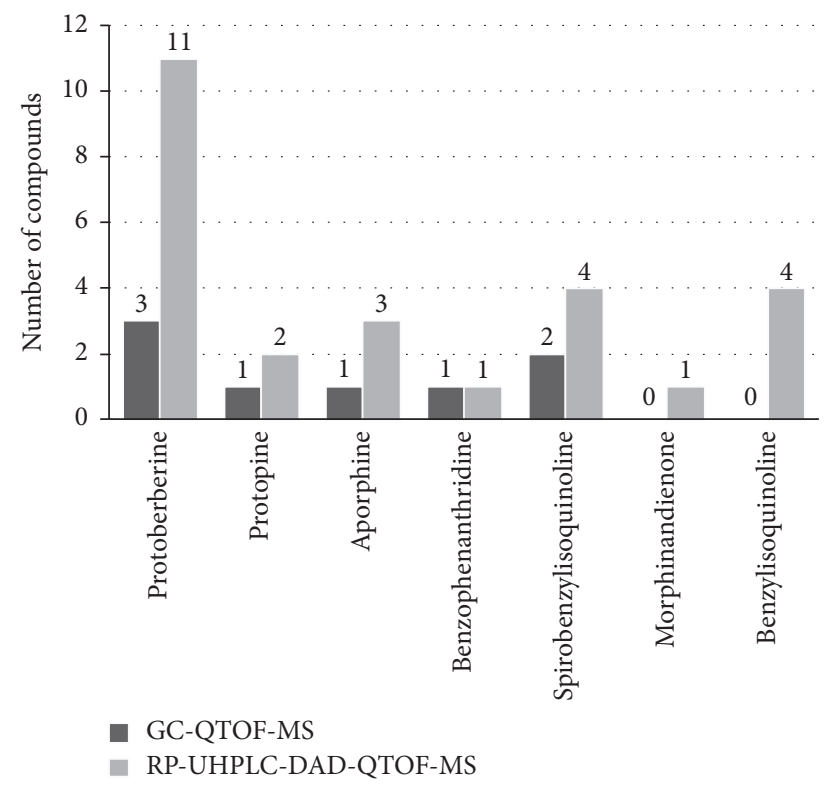

FIGURE 5: Comparison summary of the qualitative analysis of F. capreolata alkaloids by GC-QTOF-MS and RP-UHPLC-DADQTOF-MS.

\section{Disclosure}

Present affiliation of María del Mar Contreras is Department of Analytical Chemistry, University of Cordoba.

\section{Conflicts of Interest}

The authors declare no financial conflicts of interest.

\section{References}

[1] M. Asensi, The conspiracy of Cortes, Planeta, Barcelona, Spain, 2015.

[2] N. Bribi, Y. Bouguezza, and F. Maiza-Benabdesselam, "Evaluation of erythrocytes toxicity and antioxidant activity of alkaloids of Fumaria capreolata," International Journal of Pharma and Bio Sciences, vol. 4, no. 2, pp. 770-776, 2013.

[3] M. Jameel, A. Ali, and M. Ali, "New phytoconstituents from the aerial parts of Fumaria parviflora Lam," Journal of Advanced Pharmaceutical Technology and Research, vol. 5, no. 2, pp. 6469, 2014.

[4] L. Rakotondramasy-Rabesiaka, J.-L. Havet, C. Porte, and H. Fauduet, "Solid-liquid extraction of protopine from Fumaria officinalis L.-Analysis determination, kinetic reaction and model building," Separation and Purification Technology, vol. 54, no. 2, pp. 253-261, 2007.

[5] A. C. Alves de Almeida, F. M. de-Faria, R. J. Dunder, L. P. Manzo, A. R. Souza-Brito, and A. Luiz-Ferreira, "Recent trends in pharmacological activity of alkaloids in animal colitis: potential use for inflammatory bowel disease," Evid Based Complement Alternat Med, vol. 2017, Article ID 8528210, 24 pages, 2017.

[6] N. Bribi, F. Algieri, A. Rodriguez-Nogales et al., "Intestinal antiinflammatory effects of total alkaloid extract from Fumaria capreolata in the DNBS model of mice colitis and intestinal epithelial CMT93 cells," Phytomedicine, vol. 23, no. 9, pp. 901913, 2016

[7] N. Bribi, F. Algieri, A. Rodriguez-Nogales et al., "Antinociceptive and anti-inflammatory effects of total alkaloid extract from fumaria capreolata," Evidence-based Complementary and Alternative Medicine, vol. 2015, Article ID 736895, 2015.

[8] A. Crozier, M. N. Clifford, and H. Ashihara, Plant Secondary Metabolites Occurrence, Structure and Role in the Human Diet Edited by, 2006.

[9] P. Forgacs, J. Provost, A. Touche, and A. Jehanno, "Alkaloids from Fumaria capreolata and Fumaria bella," Journal of Natural Products, vol. 49, no. 1, pp. 178-179, 1986.

[10] A. P. M. Egydio, T. A. Valvassoura, and D. Y. A. C. Santos, "Geographical variation of isoquinoline alkaloids of Annona crassiflora Mart. from cerrado, Brazil," Biochemical Systematics and Ecology, vol. 46, pp. 145-151, 2013.

[11] R. Suau, B. Cabezudo, R. Rico, F. Nájera, and J. M. LópezRomero, "Direct determination of alkaloid contents in fumaria species by GC-MS," Phytochemical Analysis, vol. 13, no. 6, pp. 363-367, 2002.

[12] F. Maiza-Benabdesselam, M. Chibane, K. Madani, H. Max, and S. Adach, "Determination of isoquinoline alkaloids contents in two Algerian species of Fumaria (Fumaria capreolata and Fumaria bastardi)," African Journal of Biotechnology, vol. 6, no. 21, pp. 2487-2492, 2007.

[13] S. Berkov, J. Bastida, M. Nikolova, F. Viladomat, and C. Codina, "Rapid TLC/GC-MS identification of acetylcholinesterase inhibitors in alkaloid extracts," Phytochemical Analysis, vol. 19, no. 5, pp. 411-419, 2008.

[14] K. Bougoffa-Sadaoui, E. Gontier, M. S. Telliez, M. LequartPillon, H. Ouadid-Ahidouch, and F. Maiza-Benabdesselam, "Characterization of isoquinolin alkaloids from Fumaria agraria and evaluation of their antiproliferative activity against human breast cancer cell lines," Phytotherapie, vol. 14, no. 3, pp. $188-195,2016$

[15] L. Kursinszki, Á. Sárközi, Á. Kéry, and É. Szöke, "Improved RPHPLC method for analysis of isoquinoline alkaloids in extracts of Chelidonium majus," Chromatographia, vol. 63, no. 13, pp. S131-S135, 2006.

[16] X.-B. Luo, B. Chen, and S.-Z. Yao, "Rapid determination of protopine, allocryptopine, sanguinarine and chelerythrine in fruits of Macleaya cordata by microwave-assisted solvent and HPLC-ESI/MS," Phytochemical Analysis, vol. 17, no. 6, pp. 431438, 2006.

[17] Z. Guo, R. Cai, H. Su, and Y. Li, "Alkaloids in processed rhizoma corydalis and crude rhizoma corydalis analyzed by GC/MS," Journal of Analytical Methods in Chemistry, vol. 2014, Article ID 281342, 2014.

[18] A. Scalbert, C. Andres-Lacueva, M. Arita et al., "Databases on food phytochemicals and their health-promoting effects," Journal of Agricultural and Food Chemistry, vol. 59, no. 9, pp. 4331-4348, 2011.

[19] I. M. Abu-Reidah, M. M. Contreras, D. Arráez-Román, A. Segura-Carretero, and A. Fernández-Gutiérrez, "Reversedphase ultra-high-performance liquid chromatography coupled to electrospray ionization-quadrupole-time-of-flight mass spectrometry as a powerful tool for metabolic profiling of vegetables: Lactuca sativa as an example of its application," Journal of Chromatography A, vol. 1313, pp. 212-227, 2013.

[20] S. Ammar, M. d. M. Contreras, O. Belguith-Hadrich, A. SeguraCarretero, and M. Bouaziz, "Assessment of the distribution 
of phenolic compounds and contribution to the antioxidant activity in Tunisian fig leaves, fruits, skins and pulps using mass spectrometry-based analysis," Food \& Function, vol. 6, pp. 3663-3677, 2015.

[21] I. M. Abu-Reidah, M. del Mar Contreras, D. Arráez-Román, A. Fernández-Gutiérrez, and A. Segura-Carretero, "UHPLC-ESIQTOF-MS-based metabolic profiling of Vicia faba L. (Fabaceae) seeds as a key strategy for characterization in foodomics," Electrophoresis, vol. 35, no. 11, pp. 1571-1581, 2014.

[22] M. del Mar Contreras, I. Borrás-Linares, M. Herranz-López, V. Micol, and A. Segura-Carretero, "Further exploring the absorption and enterocyte metabolism of quercetin forms in the Caco-2 model using nano-LC-TOF-MS," Electrophoresis, vol. 37, no. 7-8, pp. 998-1006, 2016.

[23] M. Del Mar Contreras, B. Gómez-Sala, P. J. Martín-Álvarez, L. Amigo, M. Ramos, and I. Recio, "Monitoring the largescale production of the antihypertensive peptides RYLGY and AYFYPEL by HPLC-MS," Analytical and Bioanalytical Chemistry, vol. 397, no. 7, pp. 2825-2832, 2010.

[24] S. Khamtache-Abderrahim, M. Lequart-Pillon, E. Gontier et al., "Isoquinoline alkaloid fractions of Fumaria officinalis: Characterization and evaluation of their antioxidant and antibacterial activities," Industrial Crops and Products, vol. 94, pp. 1001-1008, 2016.

[25] T. Tanahashi and M. H. Zenk, "Isoquinoline alkaloids from cell suspension cultures of Fumaria capreolata," Plant Cell Reports, vol. 4, no. 2, pp. 96-99, 1985.

[26] J. Soušek, D. Guédon, T. Adam et al., "Alkaloids and organic acids content of eight Fumaria species," Phytochemical Analysis, vol. 10, no. 1, pp. 6-11, 1999.

[27] B. Ding, T. T. Zhou, G. R. Fan, and Z. Y. Hong, "Qualitative and quantitative determination of ten alkaloids in traditional Chinese medicine Corydalis yanhusuo W.T. Wang by LC-MS/MS and LC-DAD," Journal of Pharmaceutical and Biomedical Analysis, vol. 45, no. 2, pp. 219-221, 2007.

[28] M. Shamma, M. J. Hillman, and C. D. Jones, "The ultraviolet spectra of protoberberines," Chemical Reviews, vol. 69, no. 6, pp. 779-784, 1969.

[29] L. Grycováa, J. Dostálc, and R. Marek, "Quaternary protoberberine alkaloids," Phytochemistry, vol. 68, no. 2, pp. 150-175, 2007.

[30] J. Schmidt, C. Boettcher, C. Kuhnt, T. M. Kutchan, and M. H. Zenk, "Poppy alkaloid profiling by electrospray tandem mass spectrometry and electrospray FT-ICR mass spectrometry after [ring-13C6]-tyramine feeding," Phytochemistry, vol. 68, no. 2, pp. 189-202, 2007.

[31] N. Grobe, T. M. Kutchan, and M. H. Zenk, "Rat CYP2D2, not $2 \mathrm{D} 1$, is functionally conserved with human CYP2D6 in endogenous morphine formation," FEBS Letters, vol. 586, no. 13, pp. 1749-1753, 2012.

[32] Y. Li, R.-J. Zeng, J.-Z. Chen et al., "Pharmacokinetics and metabolism study of isoboldine, a major bioactive component from Radix Linderae in male rats by UPLC-MS/MS," Journal of Ethnopharmacology, vol. 171, pp. 154-160, 2015.

[33] C.-H. Ma, Z.-X. Li, L.-X. Wang, Y.-H. Tang, H.-B. Xiao, and C.-G. Huang, "Identification of major alkaloids in rat urine by HPLC/DAD/ESI-MS/MS method following oral administration of cortex Phellodendri decoction," Helvetica Chimica Acta, vol. 92, no. 2, pp. 379-398, 2009.
[34] Á. M. Móricz, E. Fornal, W. Jesionek, B. Majer-Dziedzic, and I. M. Choma, "Effect-Directed Isolation and Identification of Antibacterial Chelidonium majus L. Alkaloids," Chromatographia, vol. 78, no. 9-10, pp. 707-716, 2015.

[35] M. Sun, J. Liu, C. L. Lin, L. Miao, and L. Lin, "Alkaloid profiling of the traditional Chinese medicine Rhizoma corydalis using high performance liquid chromatography-tandem quadrupole time-of-flight mass spectrometry," Acta Pharmaceutica Sinica B, vol. 4, no. 3, pp. 208-216, 2014.

[36] C. Stévigny, J.-L. H. Jiwan, R. Rozenberg, E. De Hoffmann, and J. Quetin-Leclercq, "Key fragmentation patterns of aporphine alkaloids by electrospray ionization with multistage mass spectrometry," Rapid Communications in Mass Spectrometry, vol. 18, no. 5, pp. 523-528, 2004.

[37] H. J. Shim, J. Y. Lee, B. Kim, and J. Hong, "General fragmentations of alkaloids in electrospray ionization tandem mass spectrometry," Mass Spectrometry Letters, vol. 4, no. 4, pp. 7982, 2013.

[38] J. C. Li, G. P. Li, J. H. Nie, Q. J. Yang, P. Li, and Y. S. Liu, "Third new alkaloids from corydalis impatiens," Asian Journal of Chemistry, vol. 27, no. 7, pp. 2737-2738, 2015.

[39] R. Silva, N. P. Lopes, and D. B. Silva, "Application of MALDI Mass Spectrometry in Natural Products Analysis," Planta Medica, 2016.

[40] A. Rathi, A. K. Srivastava, A. Shirwaikar, A. K. Singh Rawat, and S. Mehrotra, "Hepatoprotective potential of Fumaria indica Pugsley whole plant extracts, fractions and an isolated alkaloid protopine," Phytomedicine, vol. 15, no. 6-7, pp. 470-477, 2008.

[41] D. S. Bae, Y. H. Kim, C.-H. Pan et al., "Protopine reduces the inflammatory activity of lipopolysaccharide-stimulated murine macrophages," BMB Reports, vol. 45, no. 2, pp. 108-113, 2012.

[42] EMEA, "Q 2 (R1) validation of analytical procedures: text and methodology," Tech. Rep. CPMP/ICH/381/95 - ICH Q2 (R1), EMEA, 2006. 

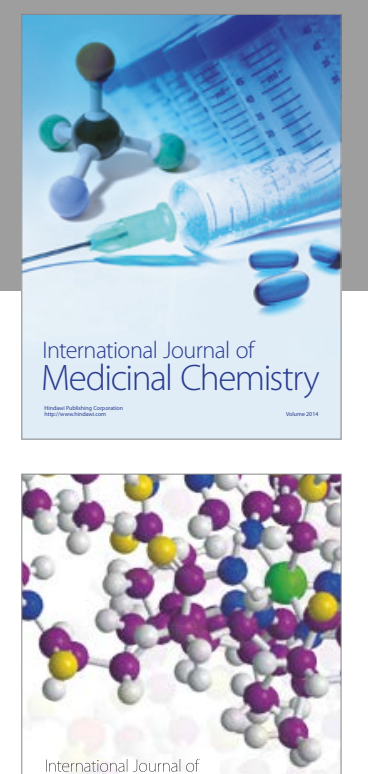

Carbohydrate Chemistry

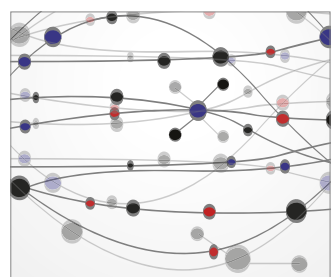

The Scientific World Journal
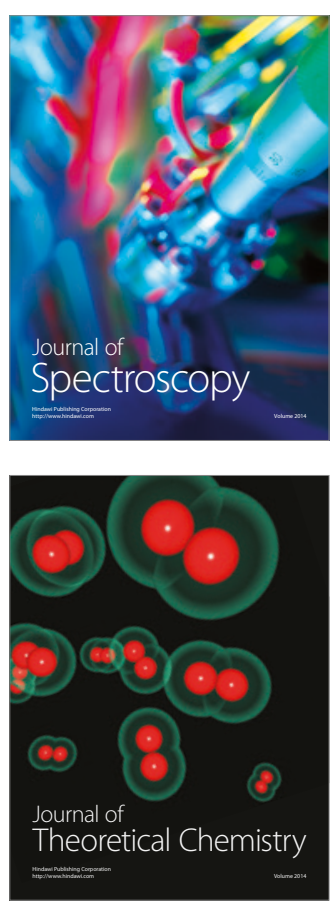
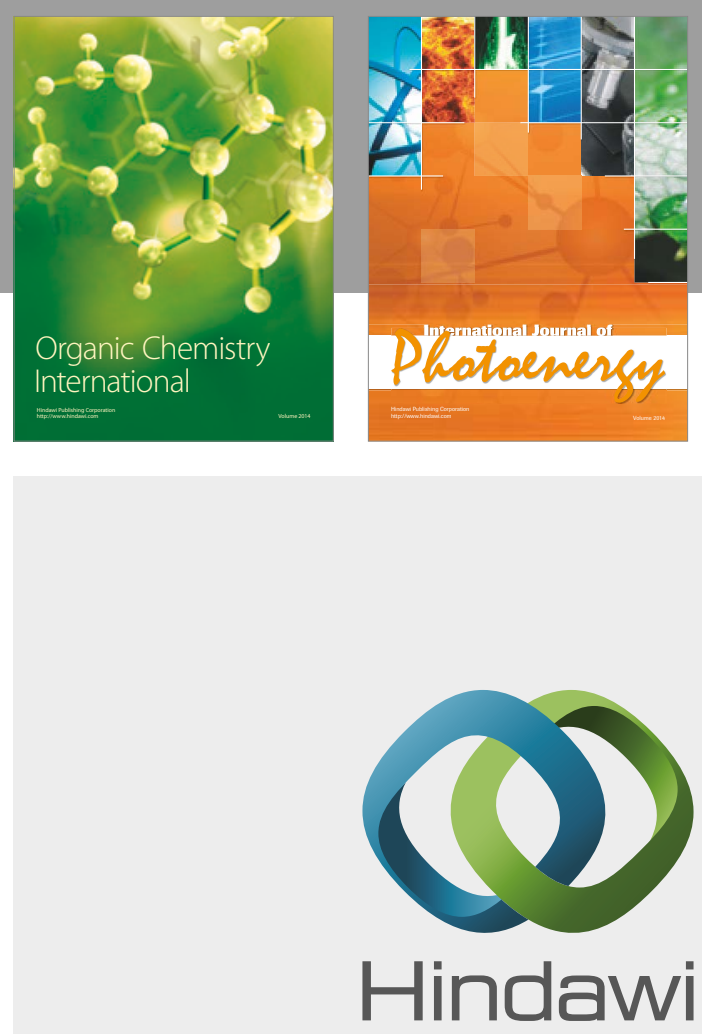

Submit your manuscripts at

https://www.hindawi.com

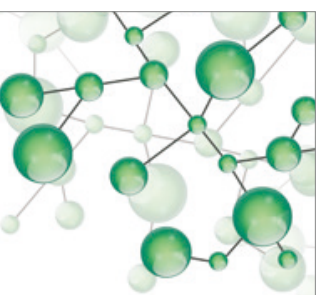

International Journal of

Inorganic Chemistry

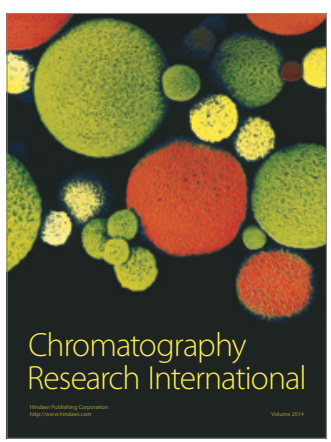

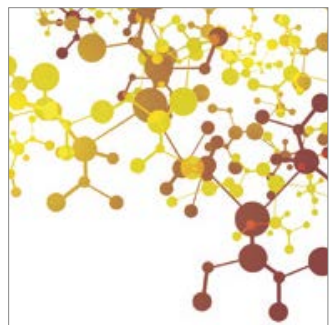

Applied Chemistry
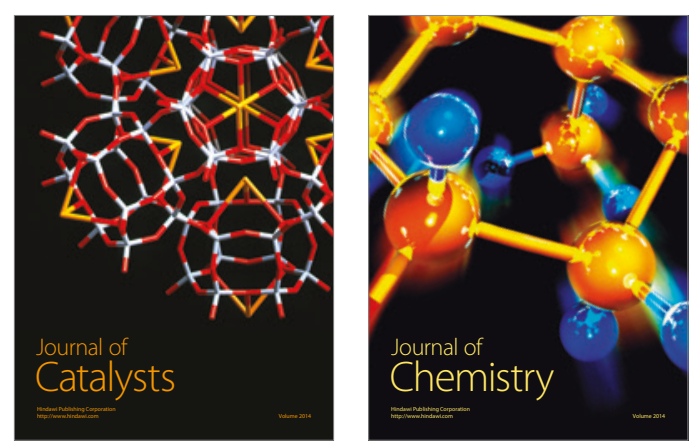
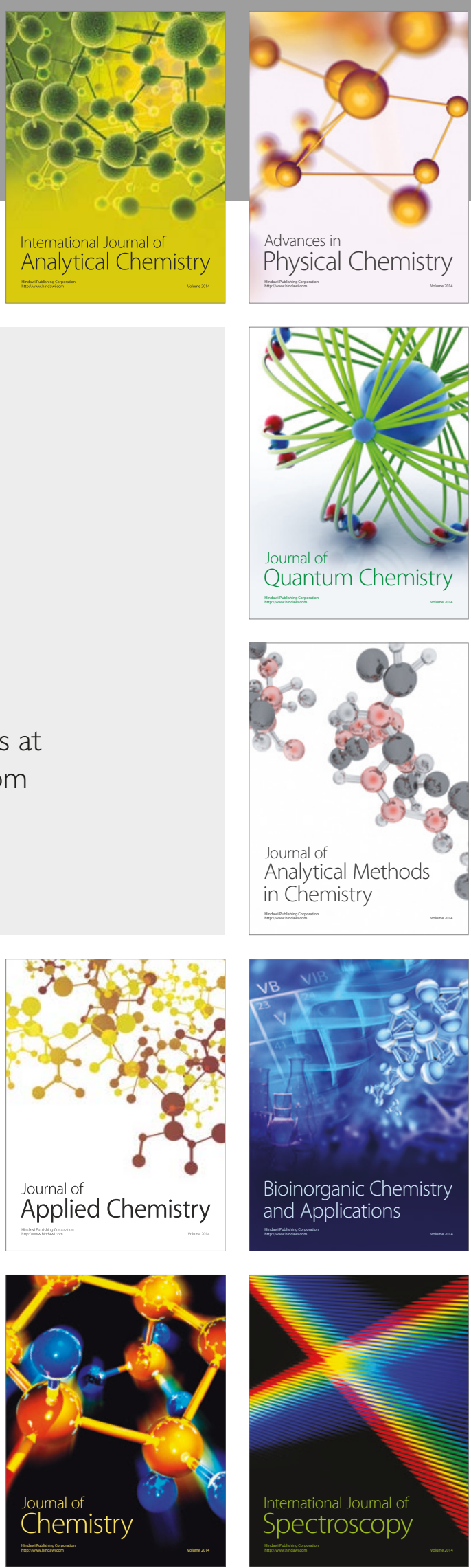